\title{
Phosphine-Free, Heterogeneous Palladium-Catalyzed Atom- Efficient Carbonylative Cross-Coupling of Triarylbismuths with Aryl Iodides: Synthesis of Biaryl Ketones
}

\author{
Wenyan Hao, Haiyi Liu, Lin Yin and Mingzhong Cai* \\ Key Laboratory of Functional Small Organic Molecule, Ministry of Education and College of \\ Chemistry \& Chemical Engineering, Jiangxi Normal University, Nanchang 330022, P. R. China \\ E-mail: mzcai@jxnu.edu.cn (M.C.)
}

\section{Supporting Information}

\section{Table of Contents}

${ }^{1} \mathrm{H}$ NMR and ${ }^{13} \mathrm{C}$ NMR Spectra of Compounds 3a-3k' $\quad$ S2-S38 


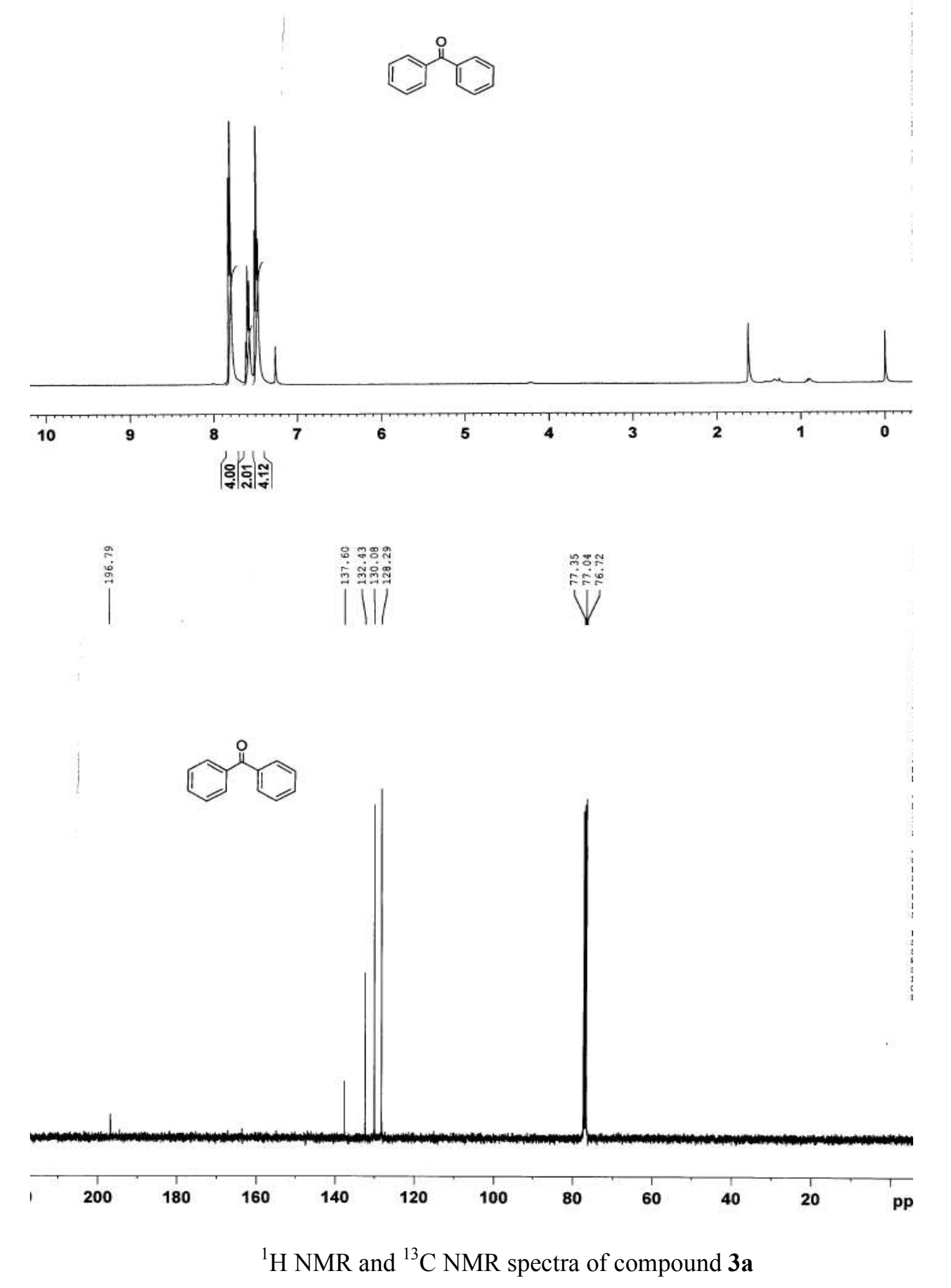




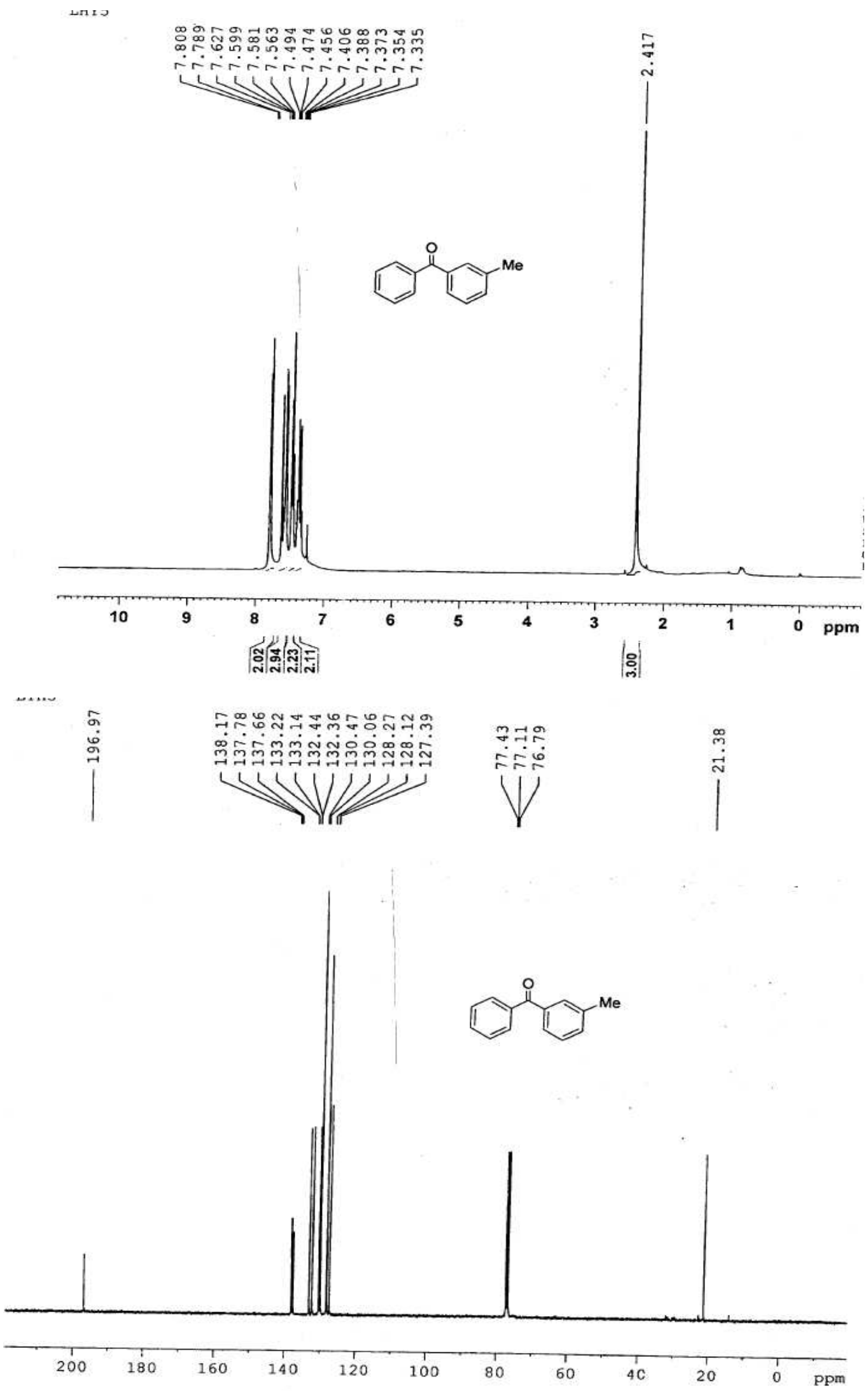

${ }^{1} \mathrm{H}$ NMR and ${ }^{13} \mathrm{C}$ NMR spectra of compound $\mathbf{3 b}$ 


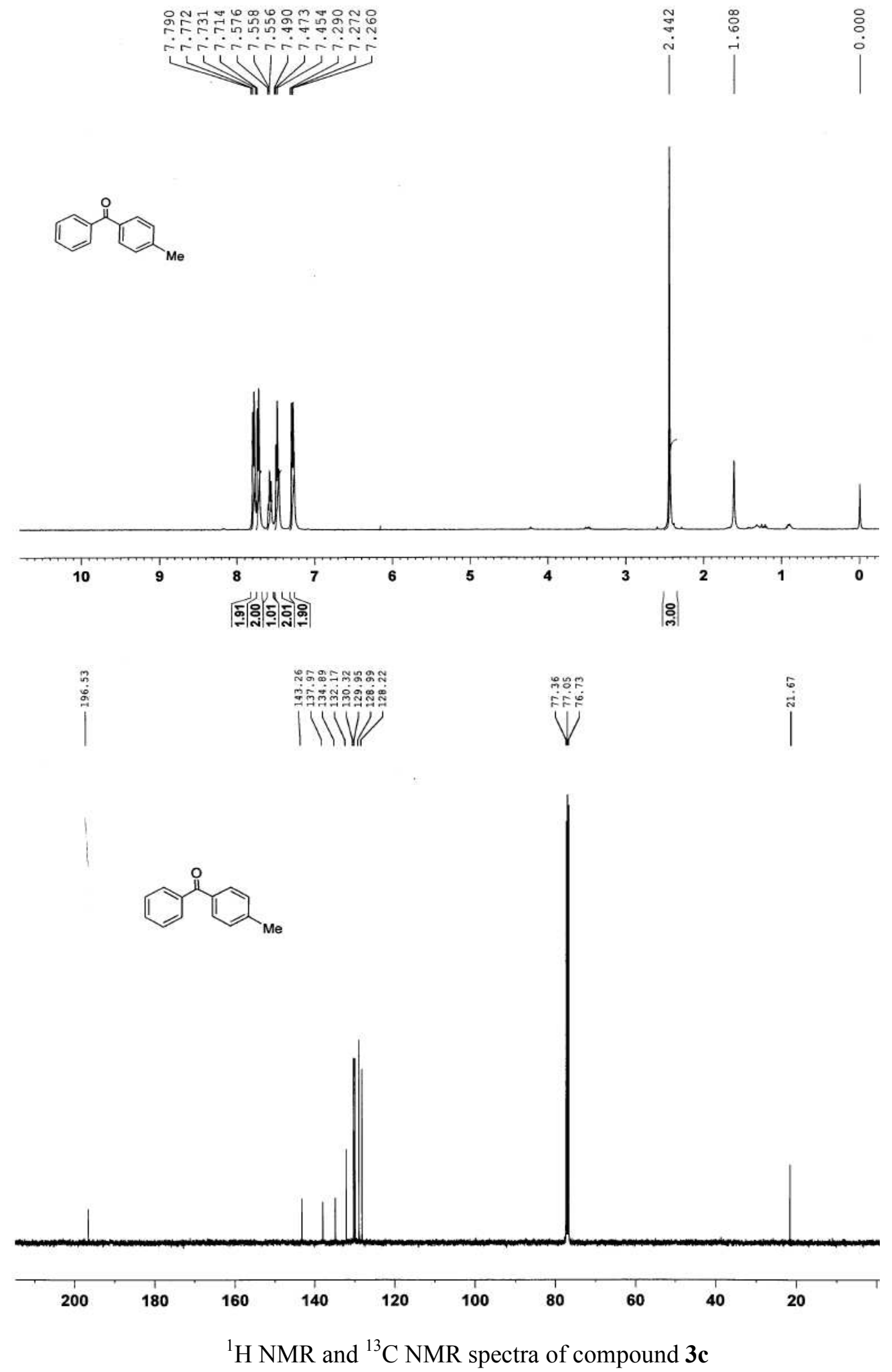




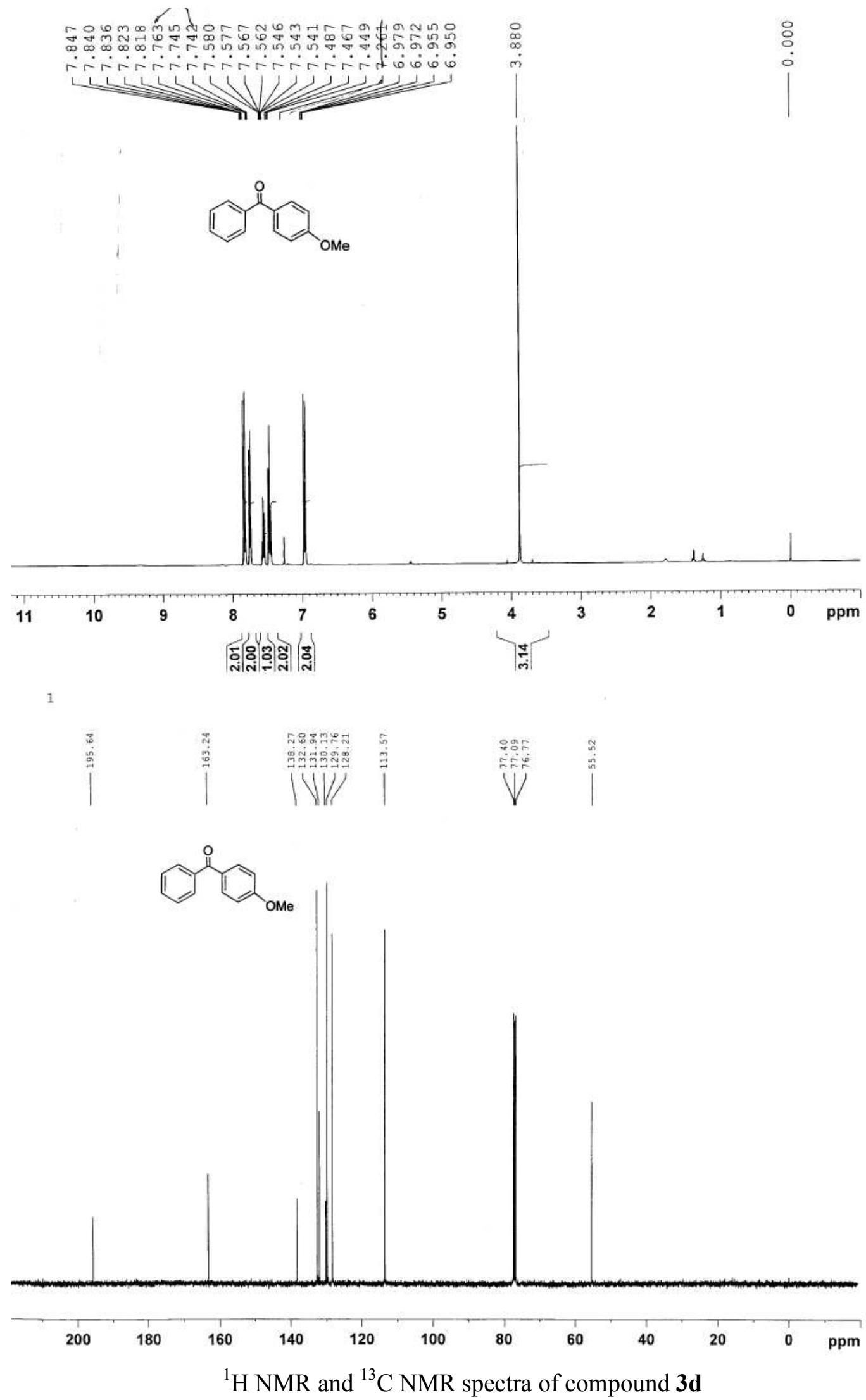




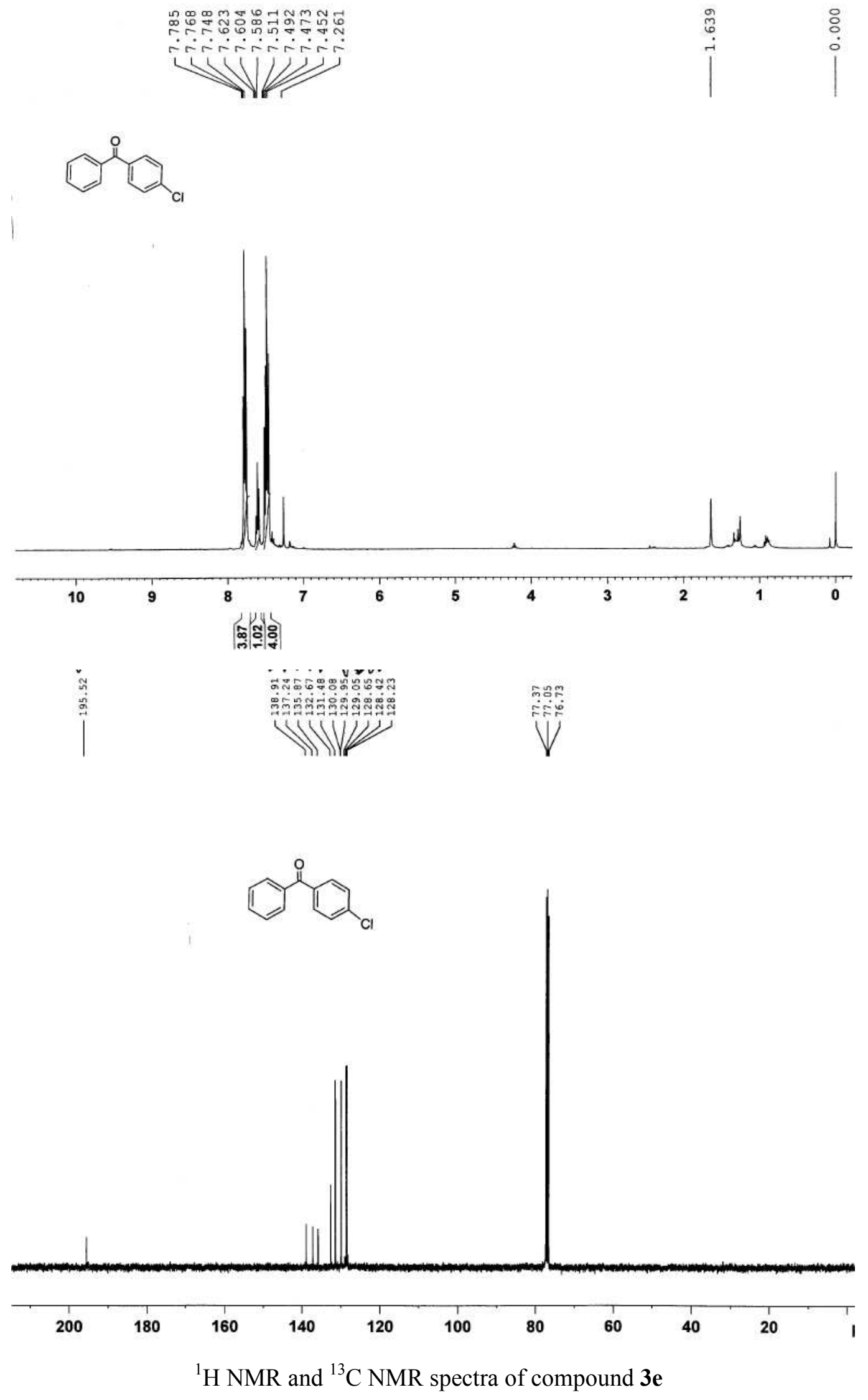



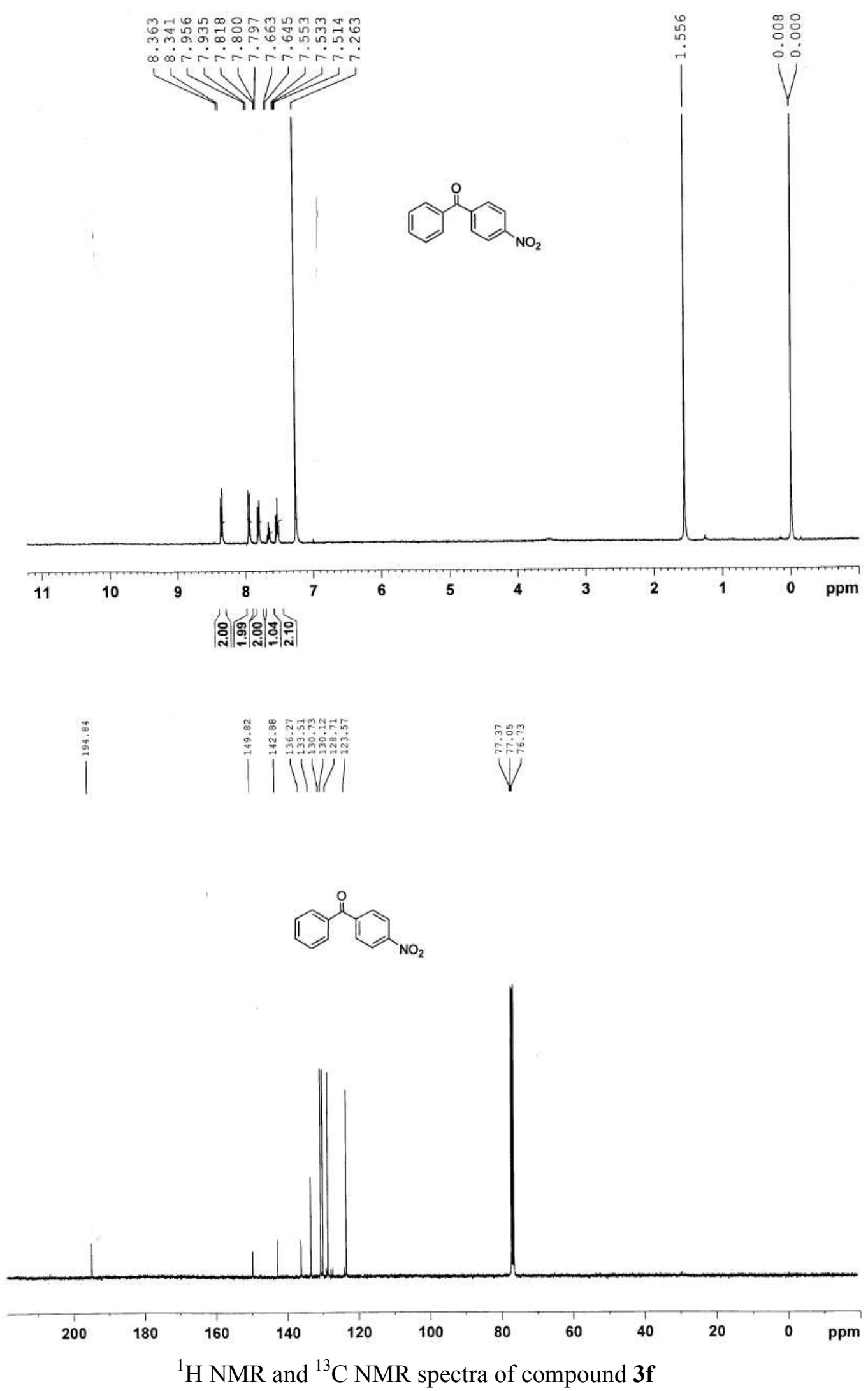


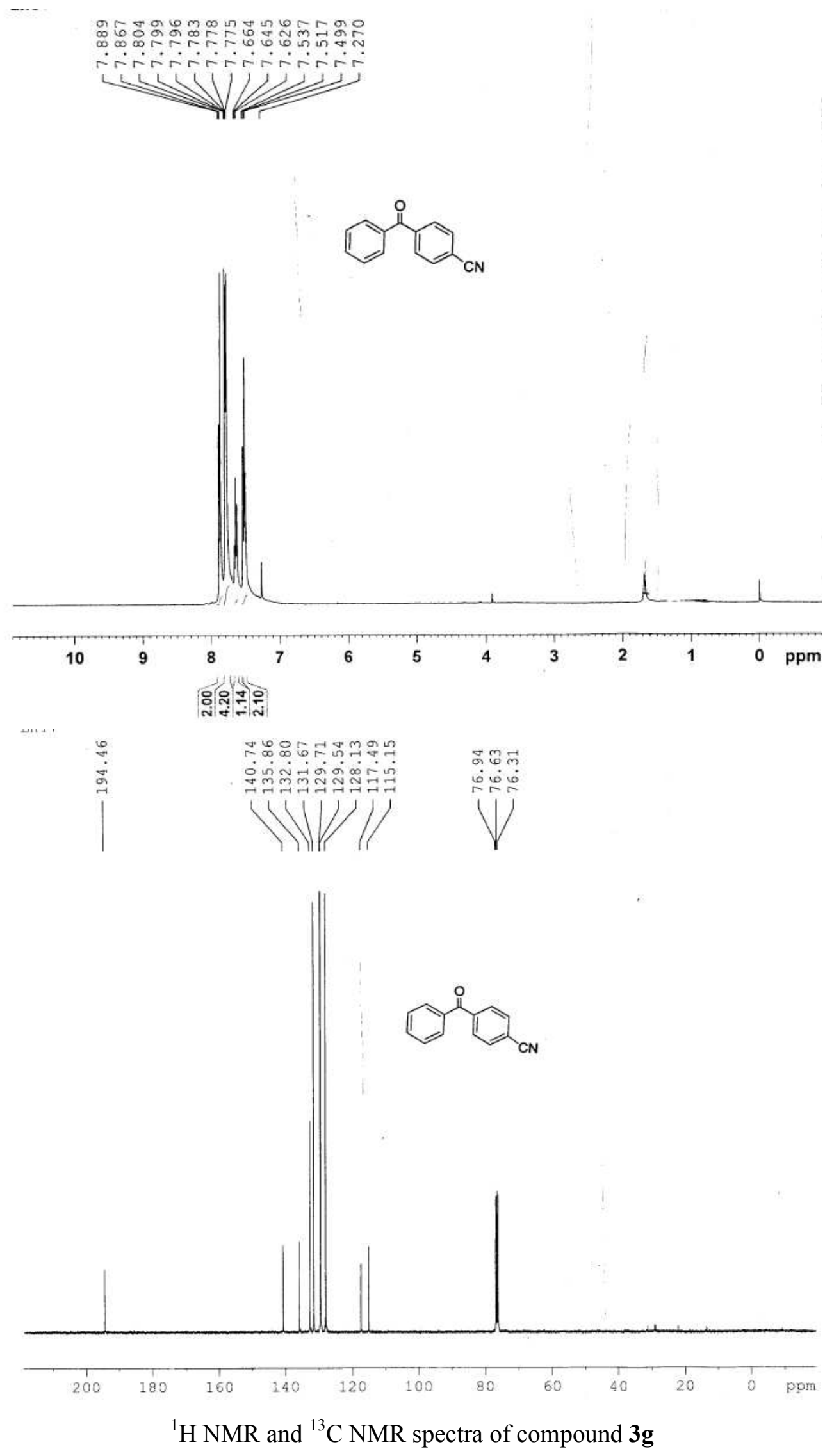



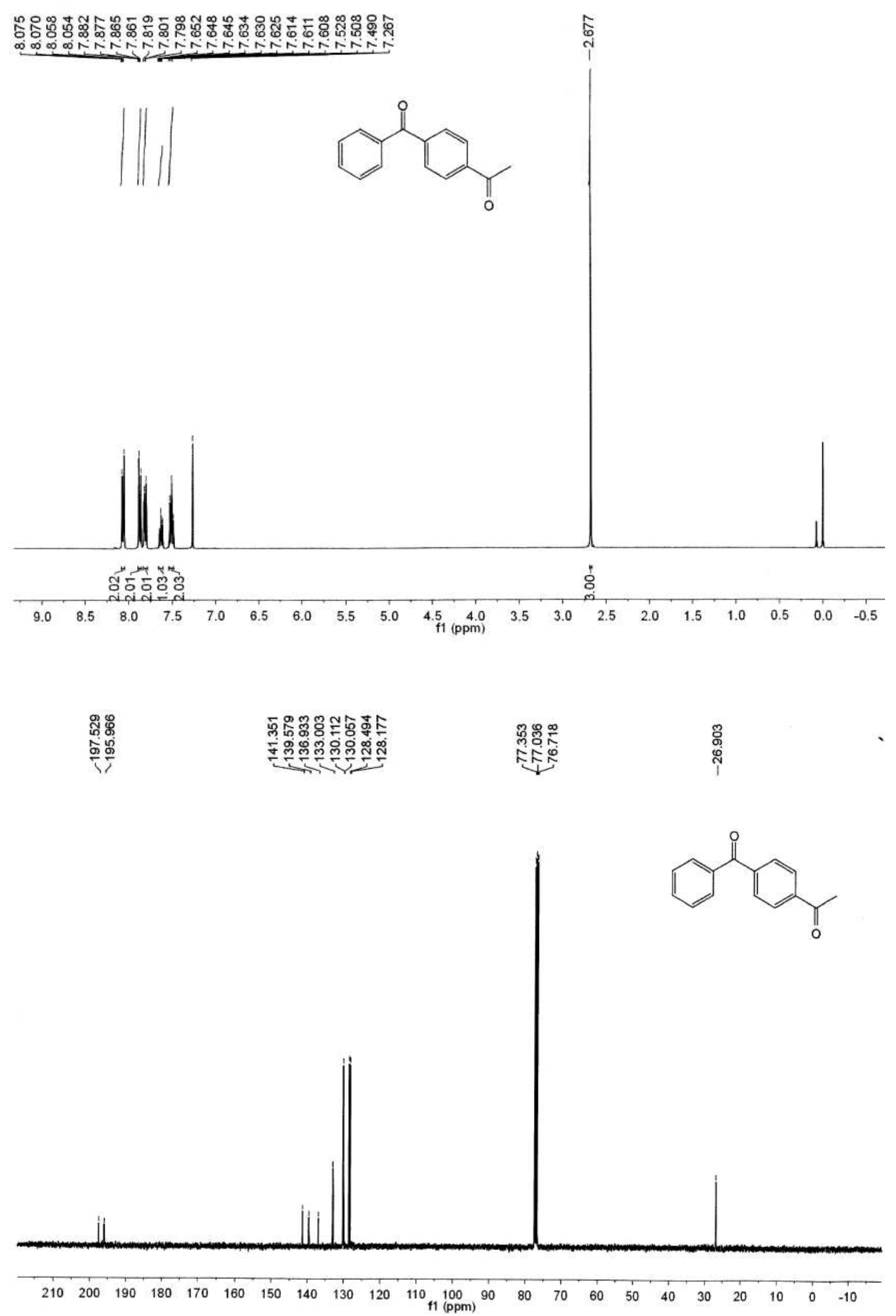

${ }^{1} \mathrm{H}$ NMR and ${ }^{13} \mathrm{C}$ NMR spectra of compound $\mathbf{3 h}$ 


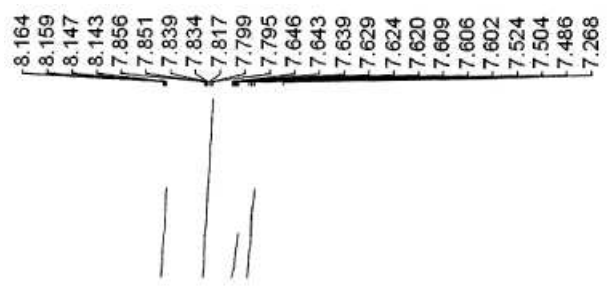

옹
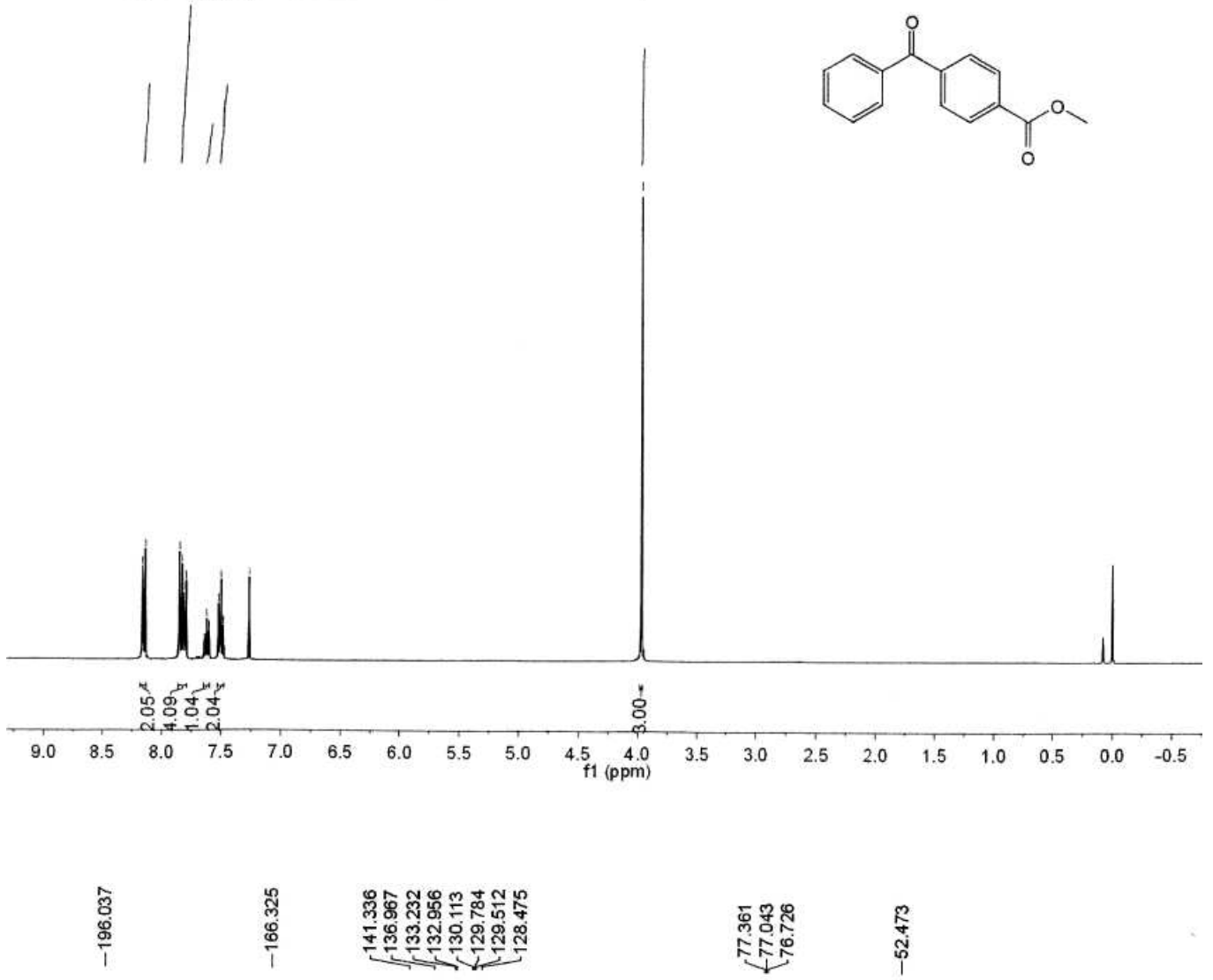

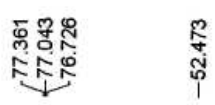

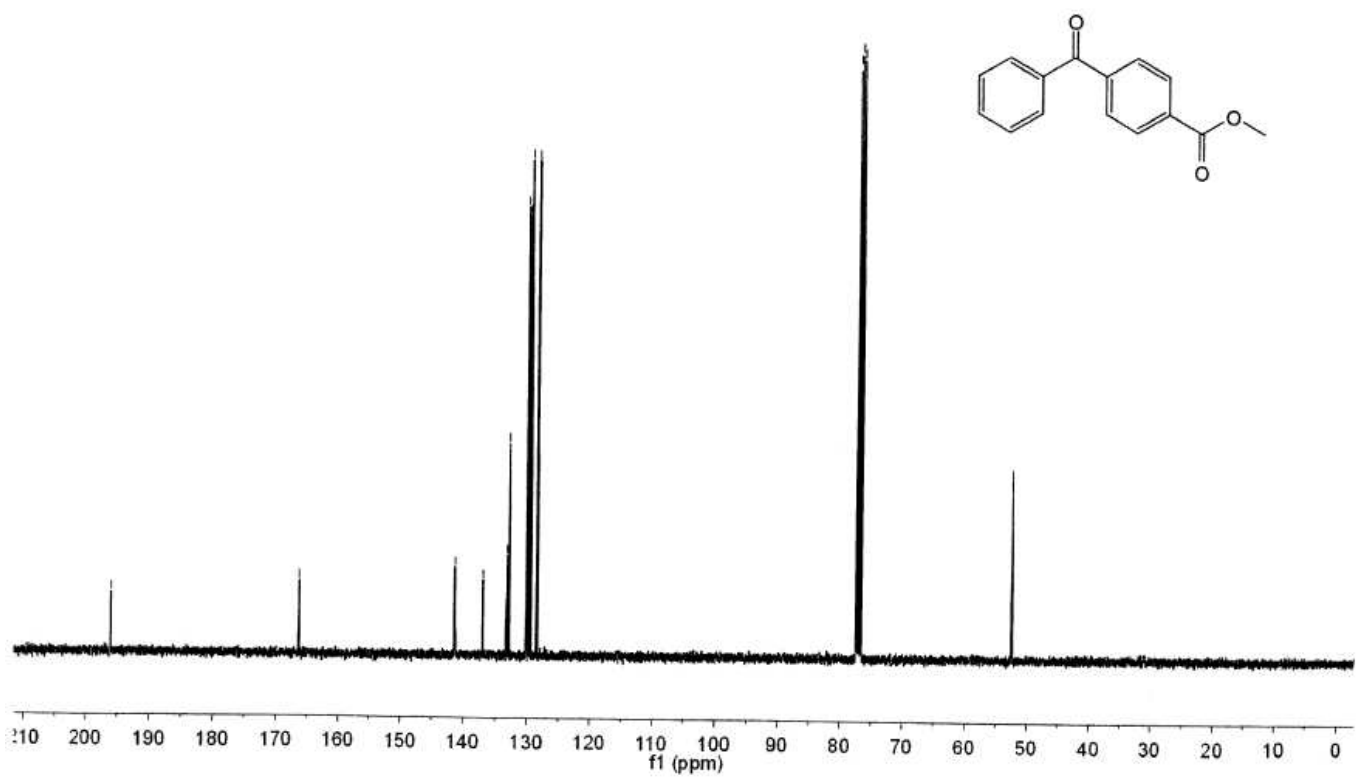

${ }^{1} \mathrm{H}$ NMR and ${ }^{13} \mathrm{C}$ NMR spectra of compound Bi

10 


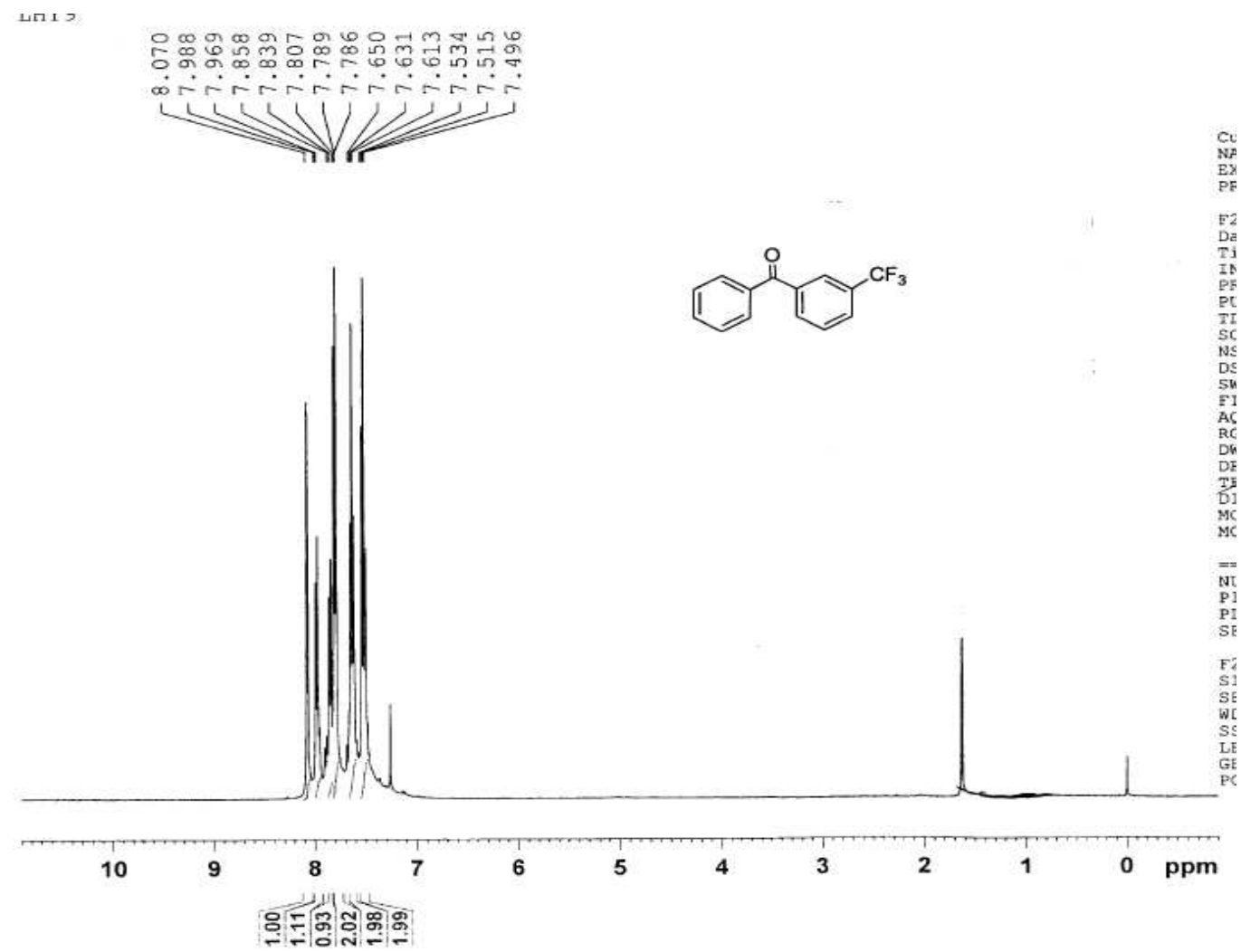

LHY 9
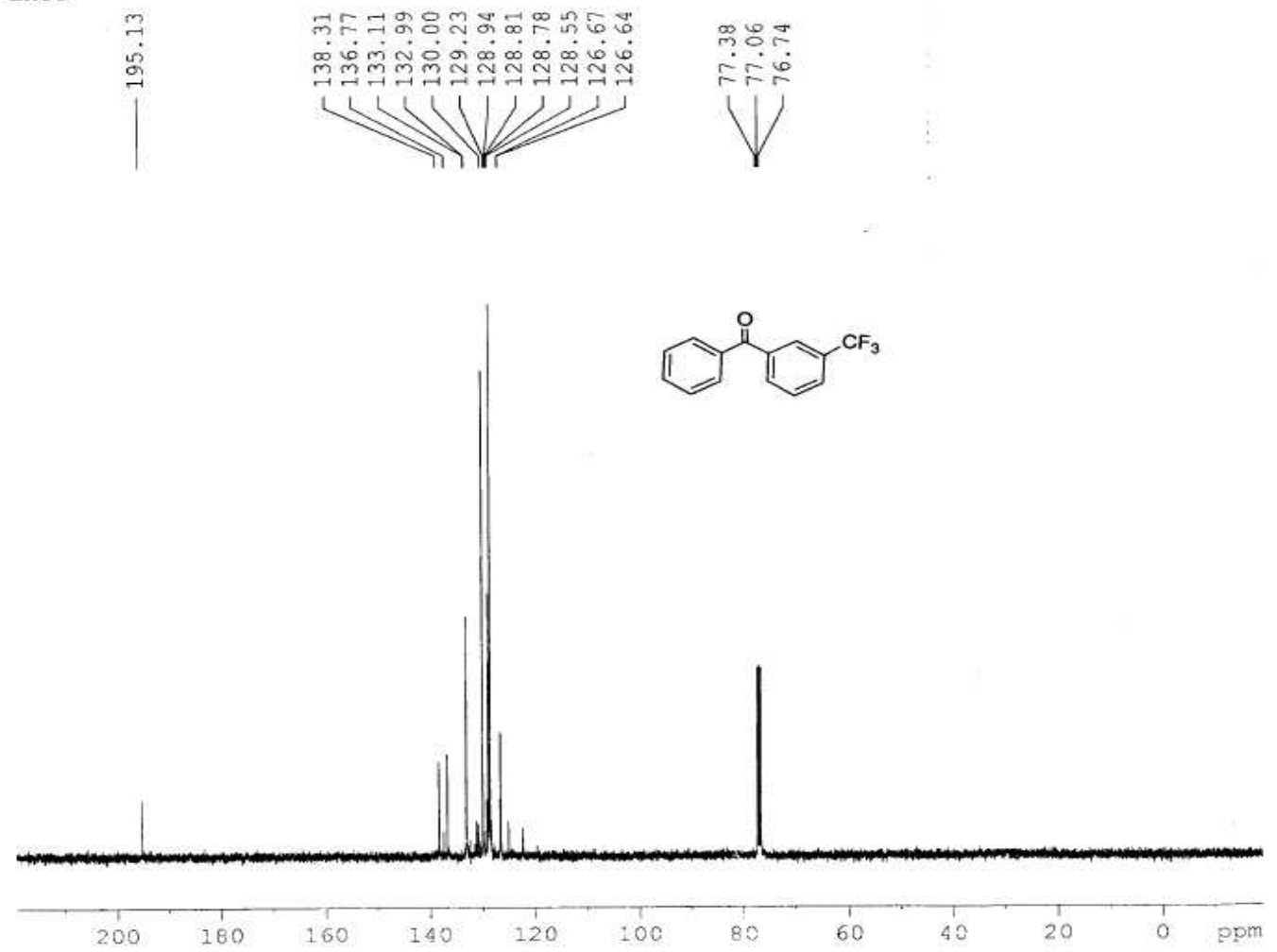

${ }^{1} \mathrm{H}$ NMR and ${ }^{13} \mathrm{C}$ NMR spectra of compound $\mathbf{3 j}$ 

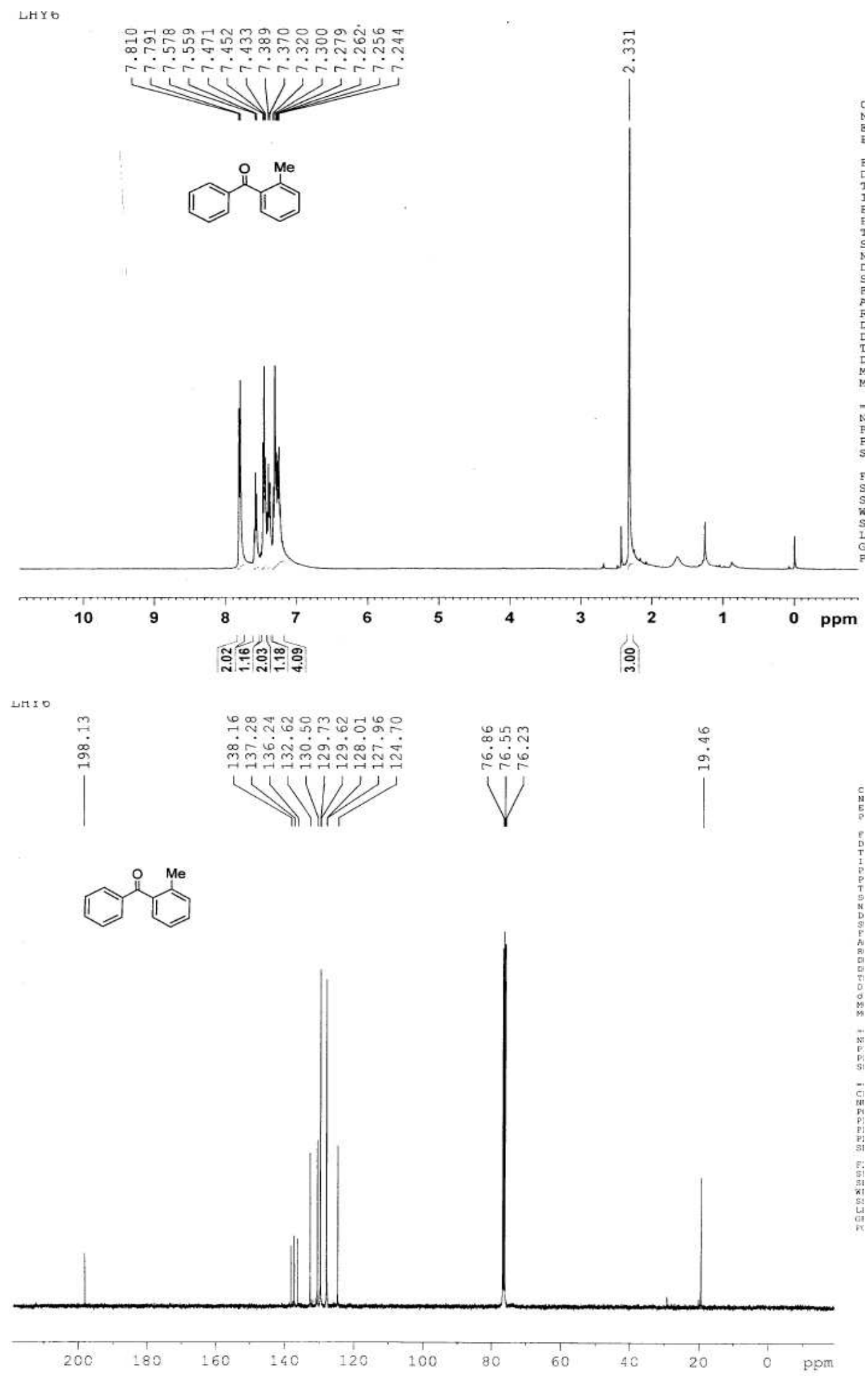

${ }^{1} \mathrm{H}$ NMR and ${ }^{13} \mathrm{C}$ NMR spectra of compound $\mathbf{3 k}$ 

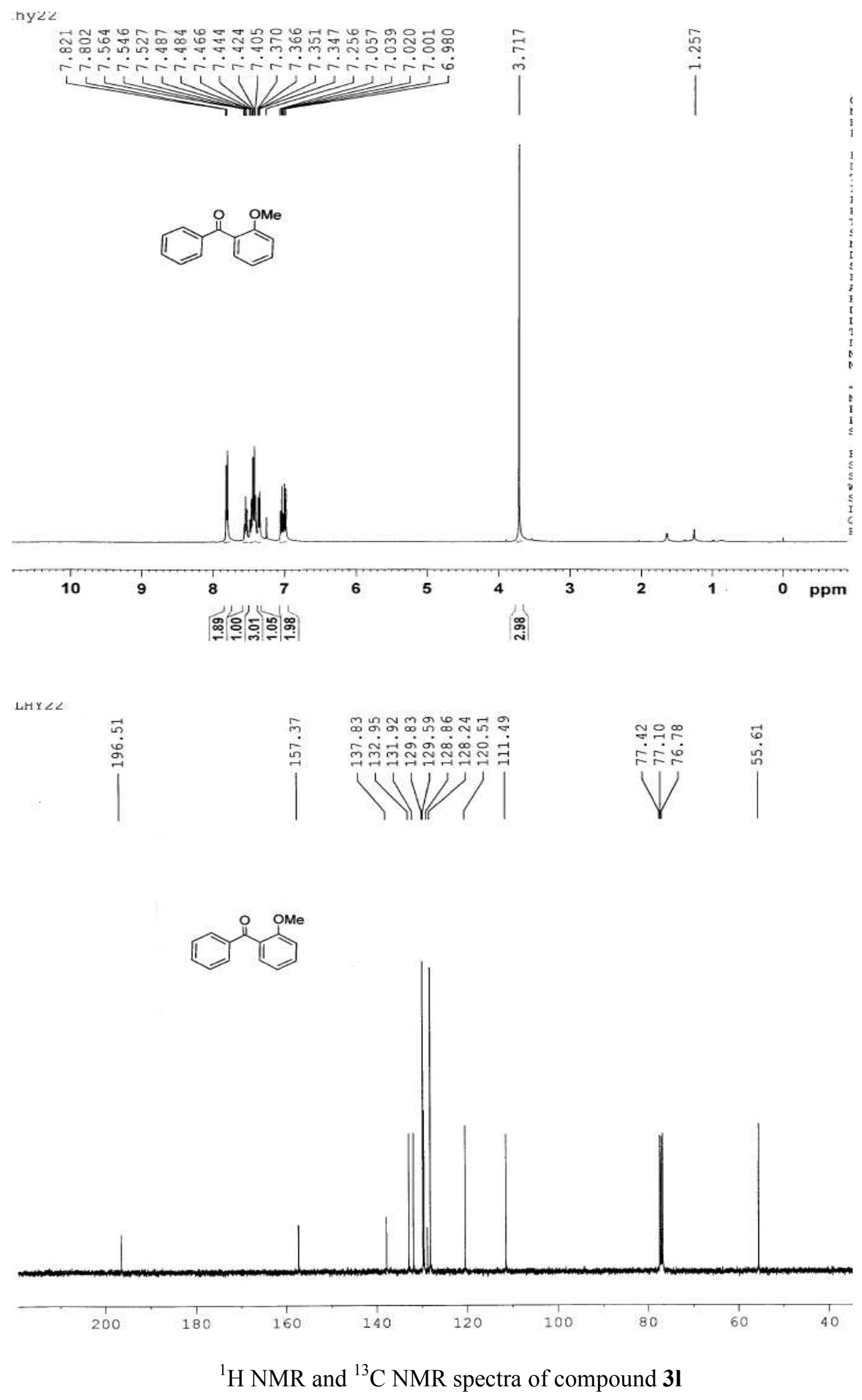

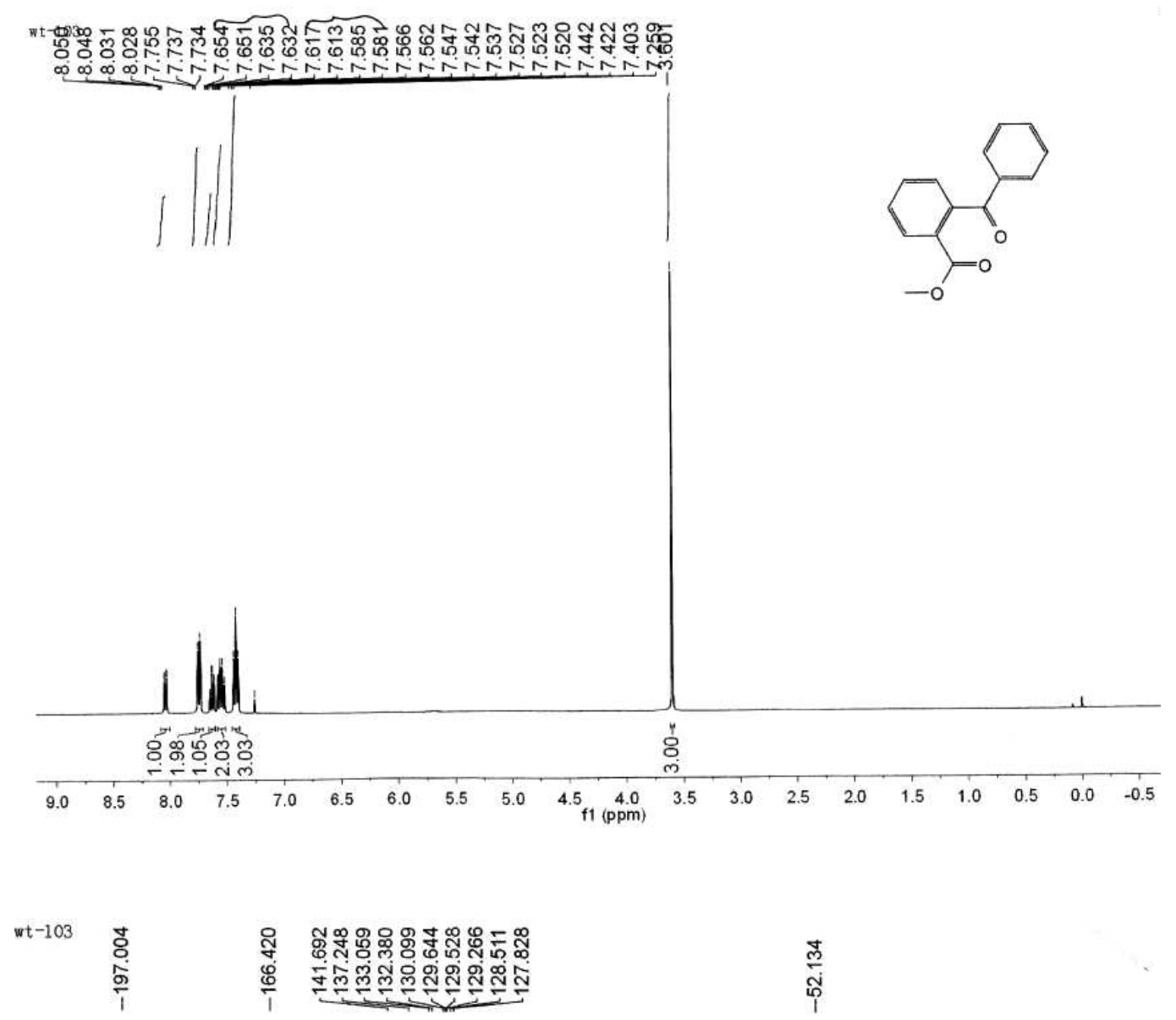

กั่

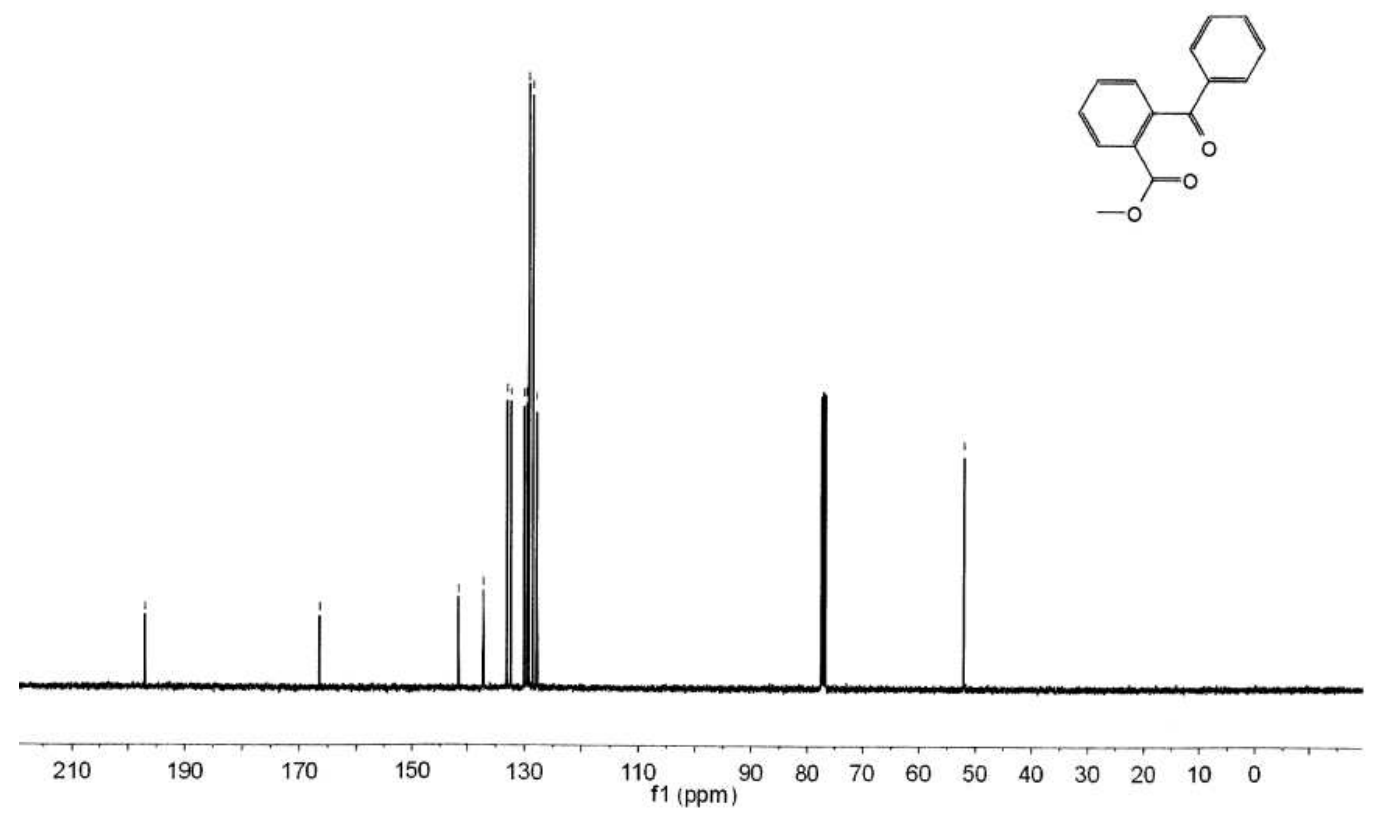

${ }^{1} \mathrm{H}$ NMR and ${ }^{13} \mathrm{C}$ NMR spectra of compound $\mathbf{3 m}$ 
Lnto

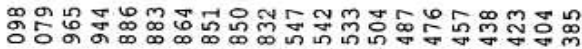

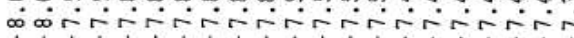

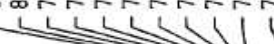

in

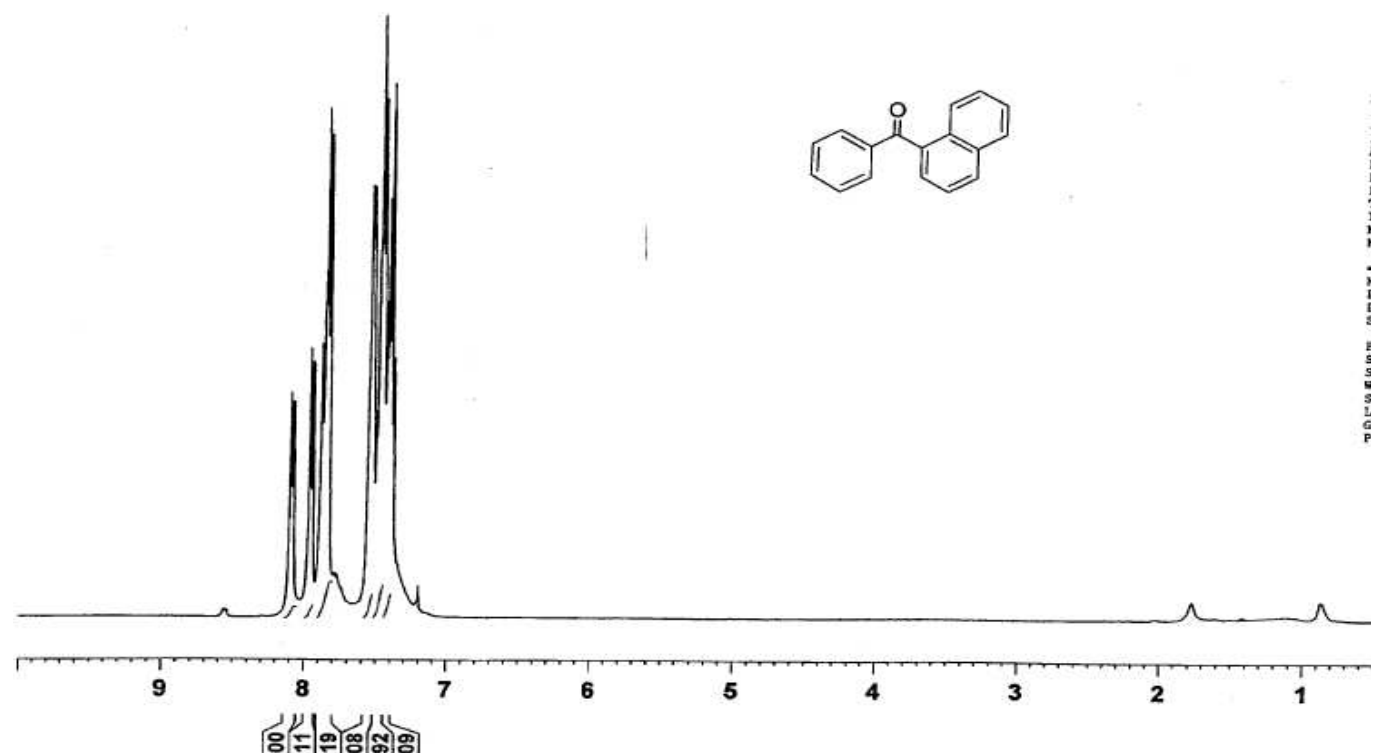

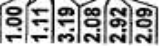

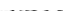
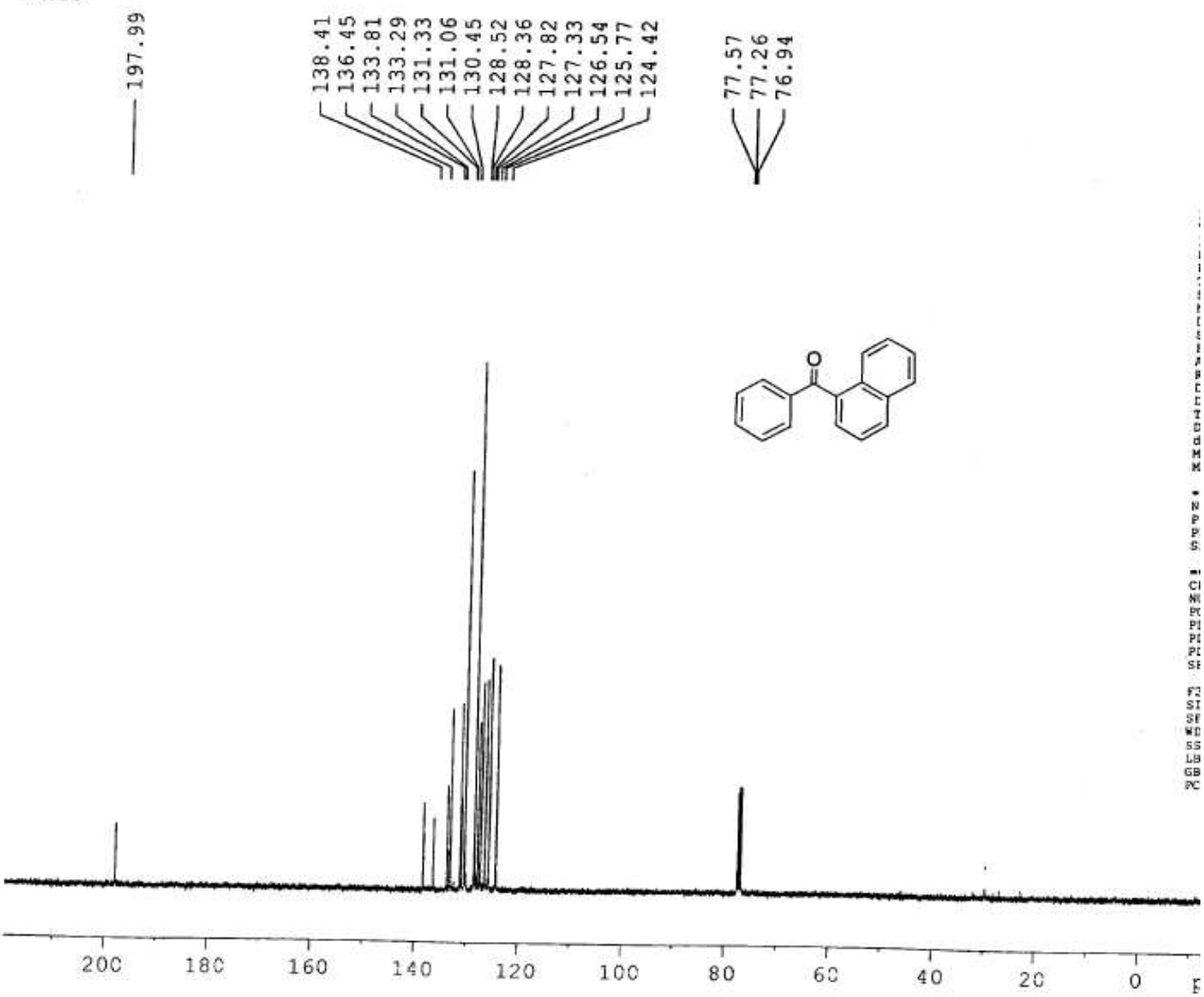

${ }^{1} \mathrm{H}$ NMR and ${ }^{13} \mathrm{C}$ NMR spectra of compound $3 \mathbf{n}$ 

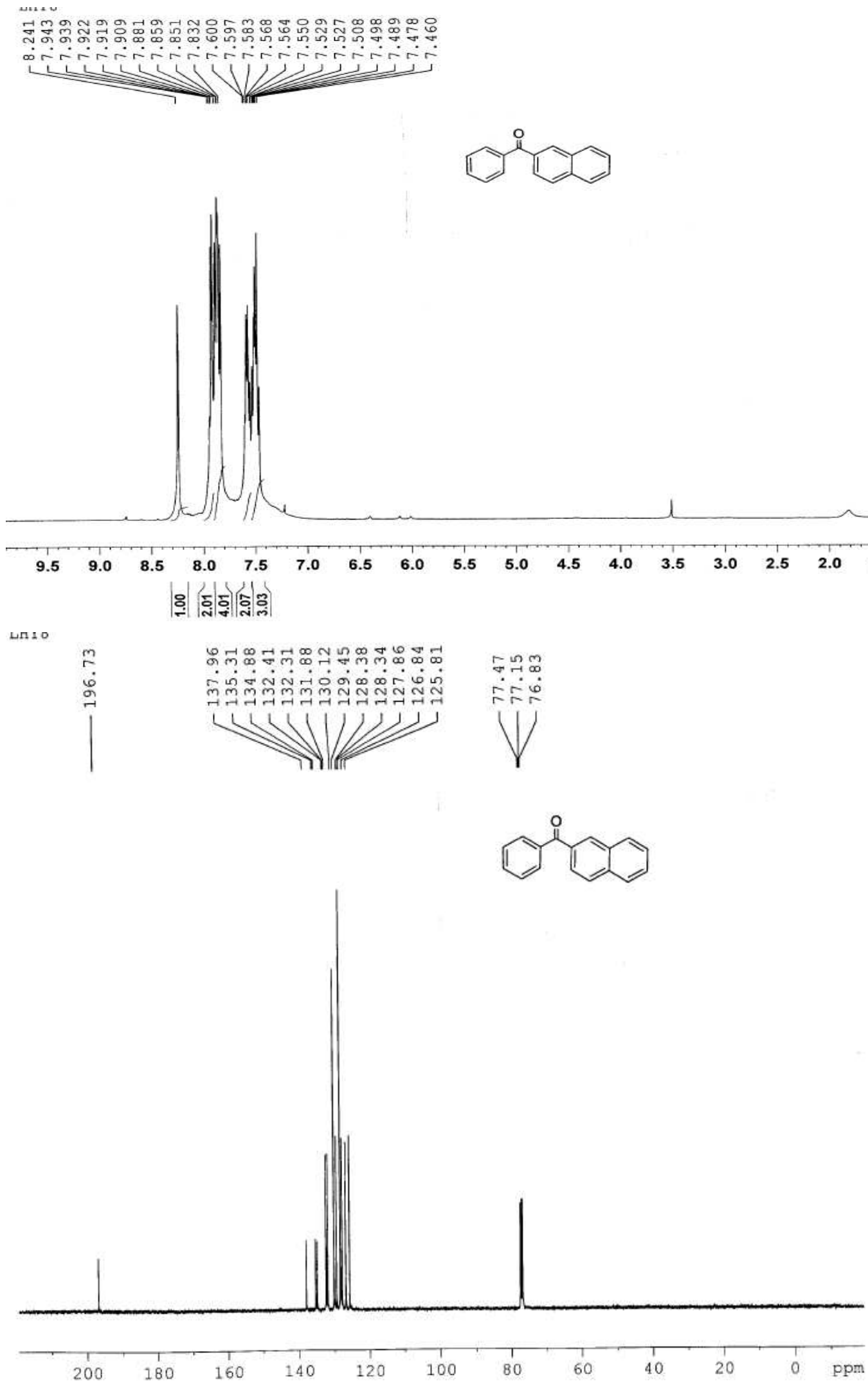

${ }^{1} \mathrm{H}$ NMR and ${ }^{13} \mathrm{C}$ NMR spectra of compound 30

16 

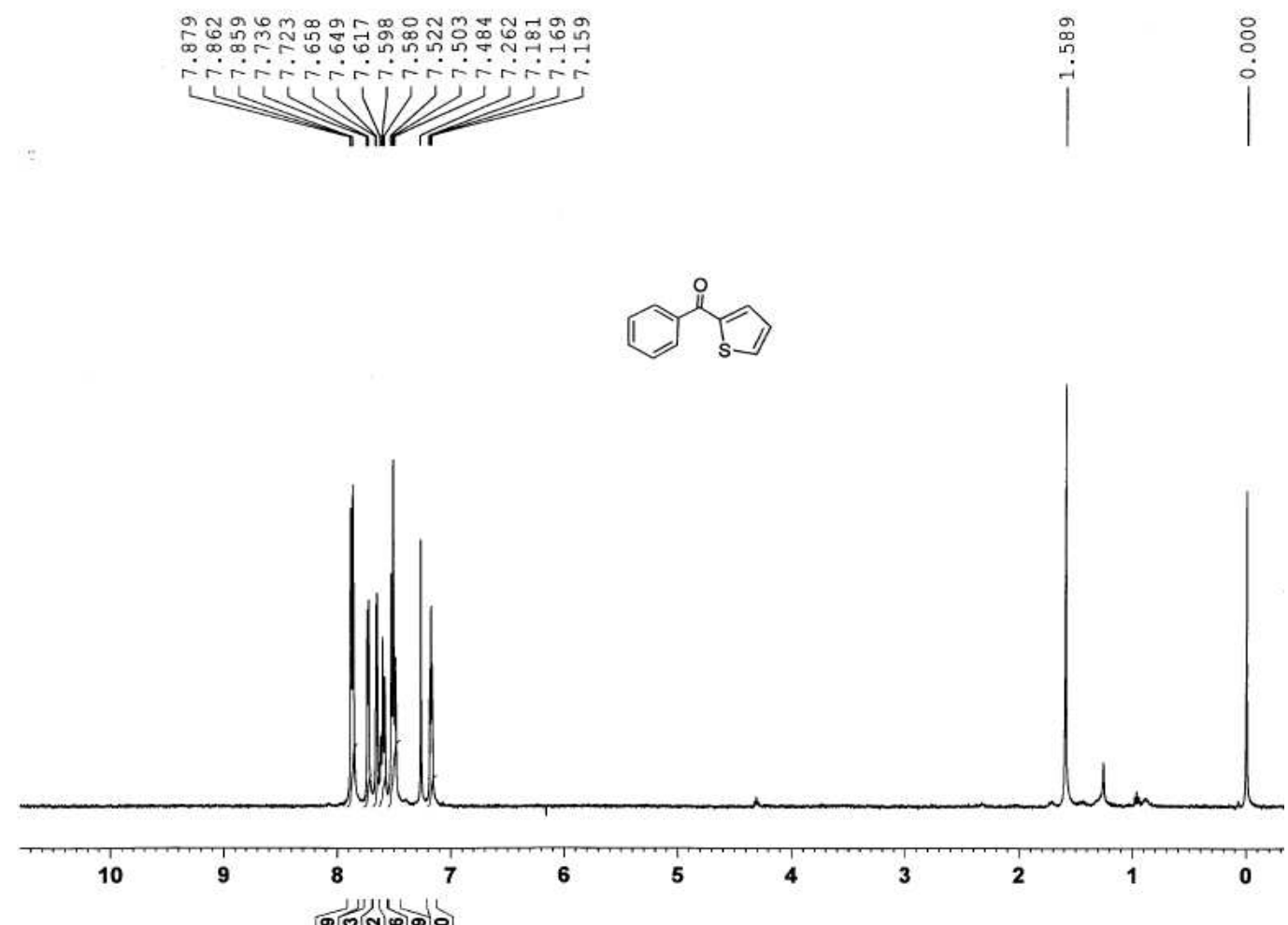

\%훙유융
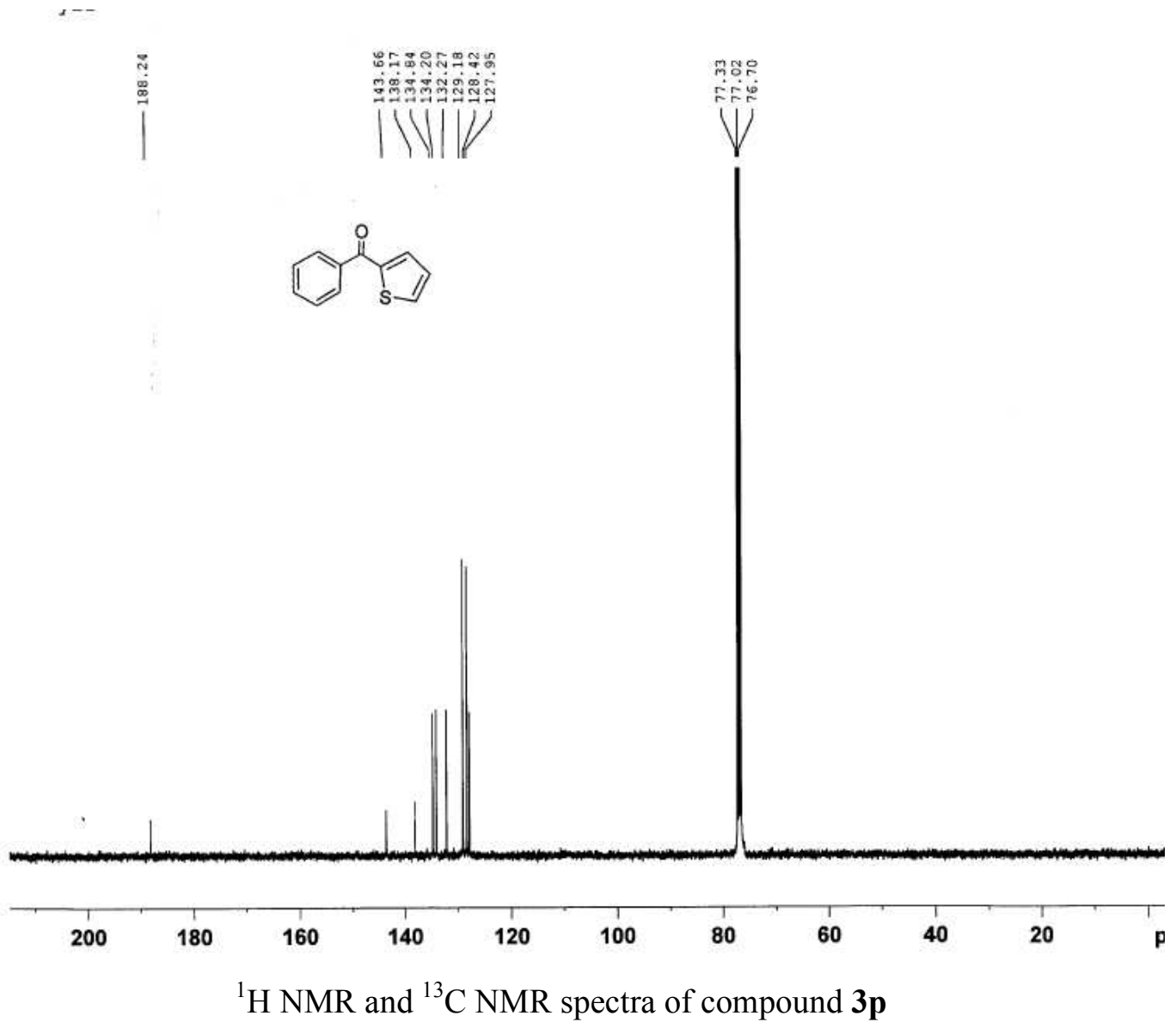


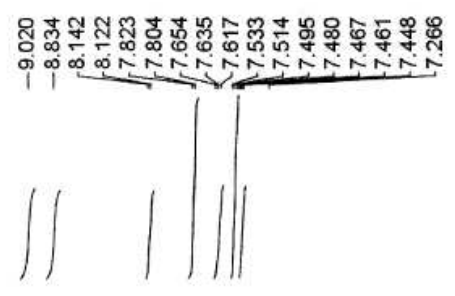

$\stackrel{8}{\circ}$

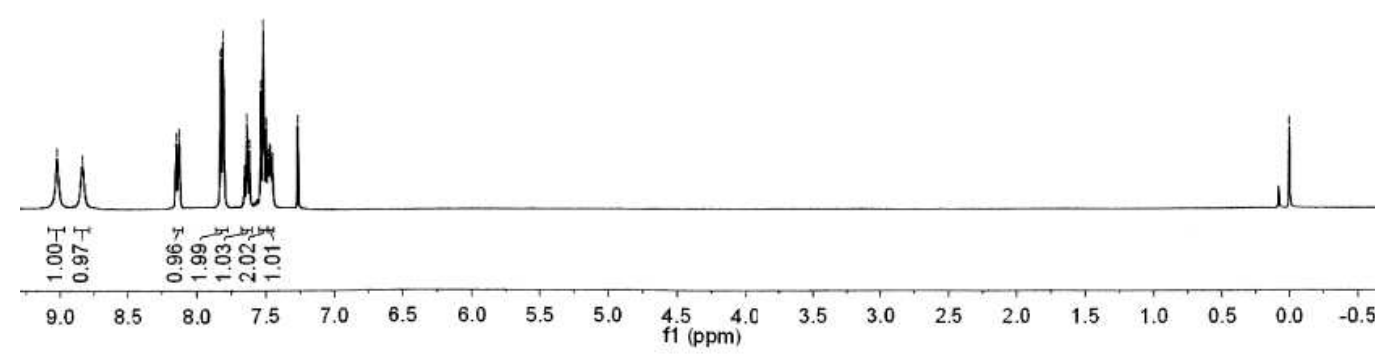

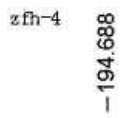

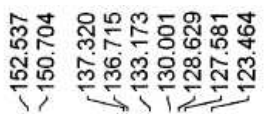
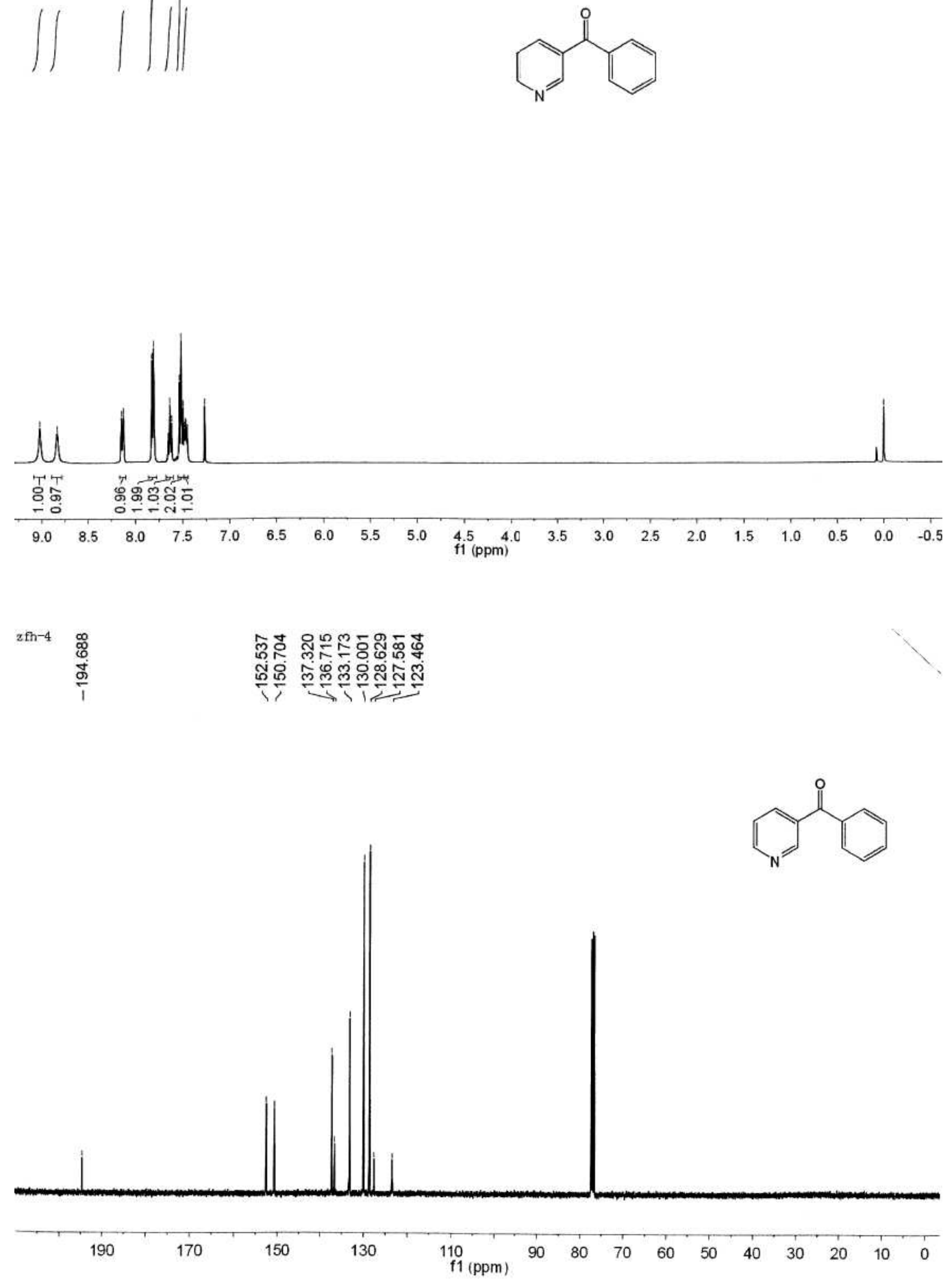

${ }^{1} \mathrm{H}$ NMR and ${ }^{13} \mathrm{C}$ NMR spectra of compound $\mathbf{3 q}$

18 

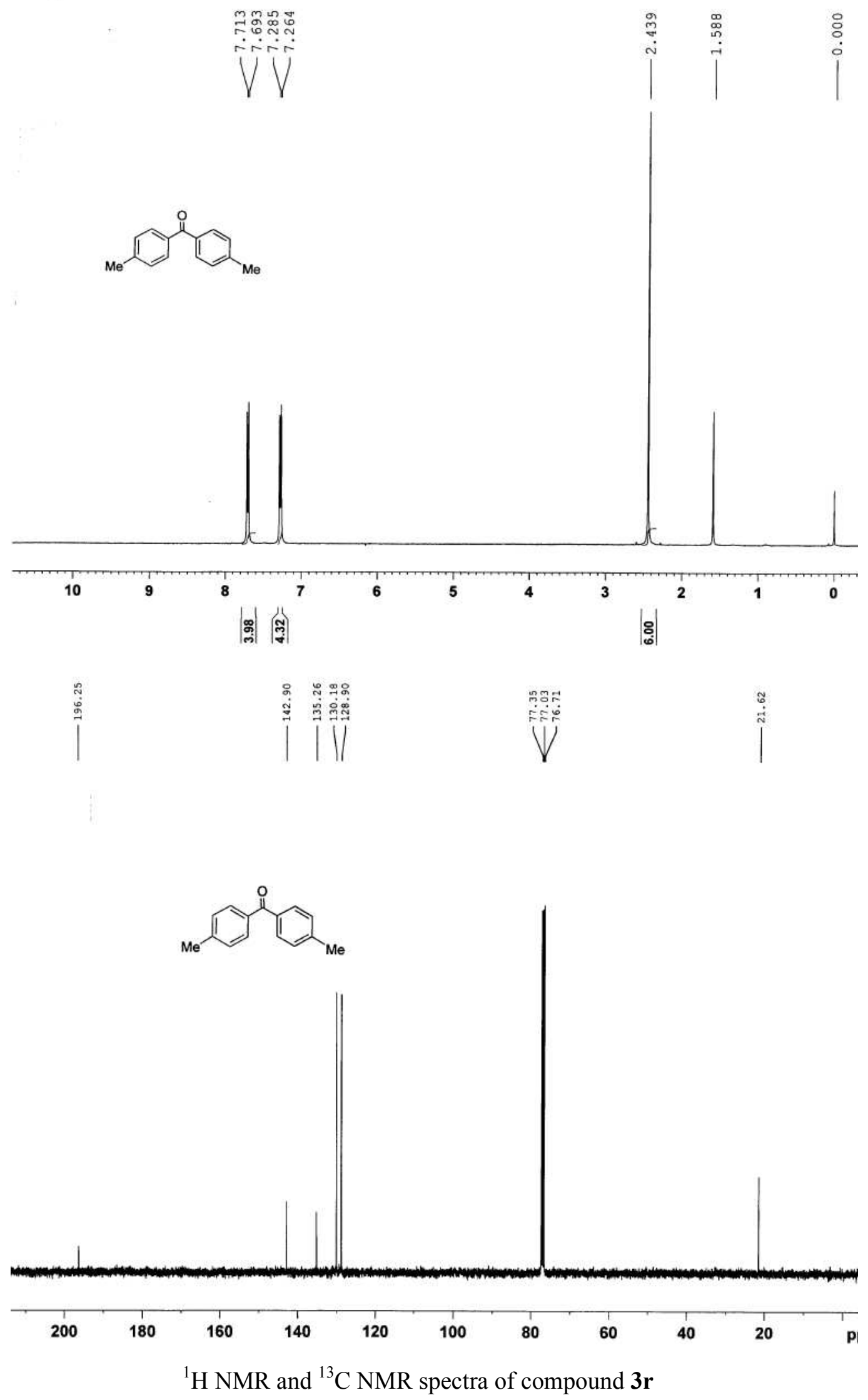

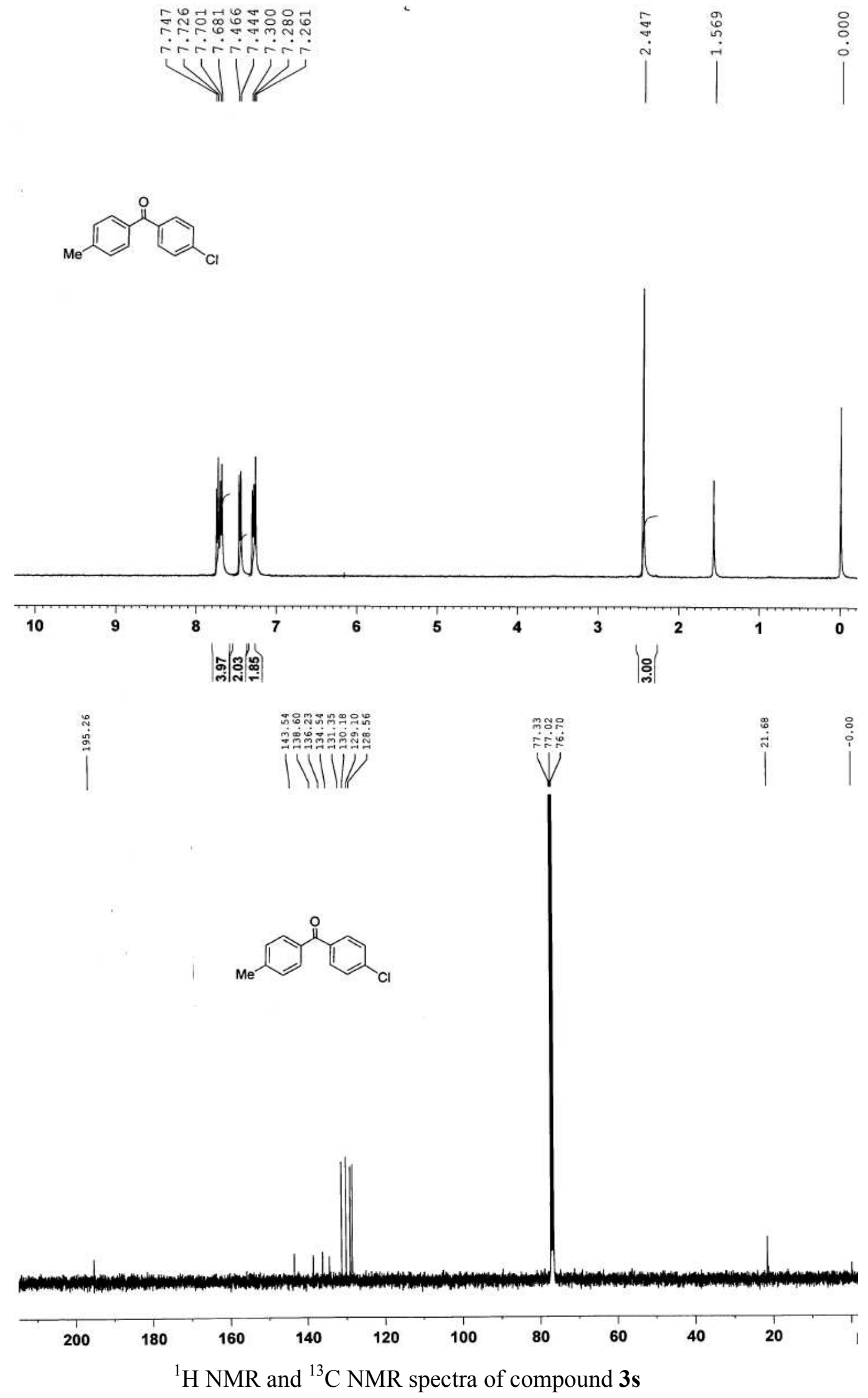


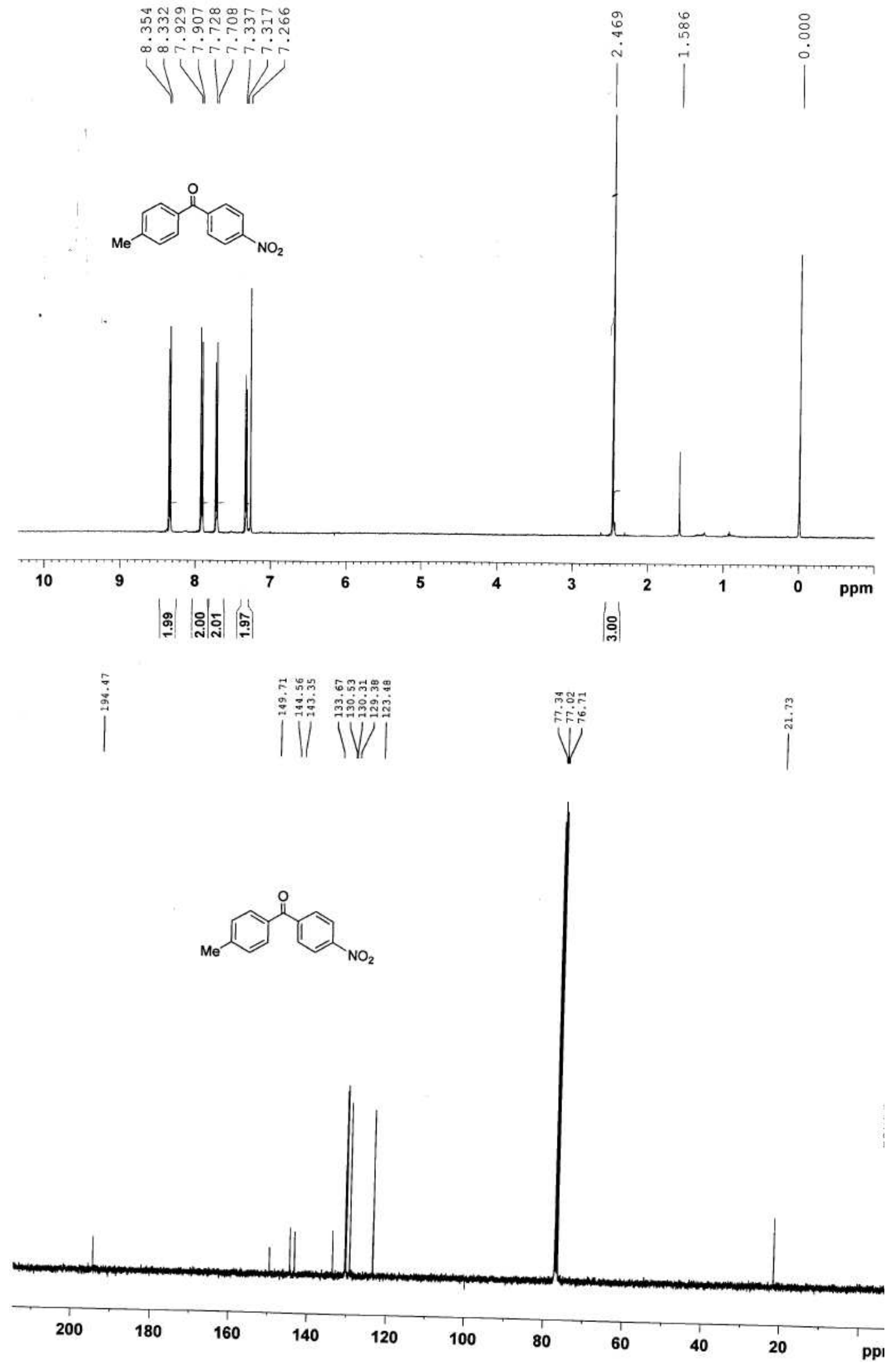

${ }^{1} \mathrm{H}$ NMR and ${ }^{13} \mathrm{C}$ NMR spectra of compound $\mathbf{3 t}$ 

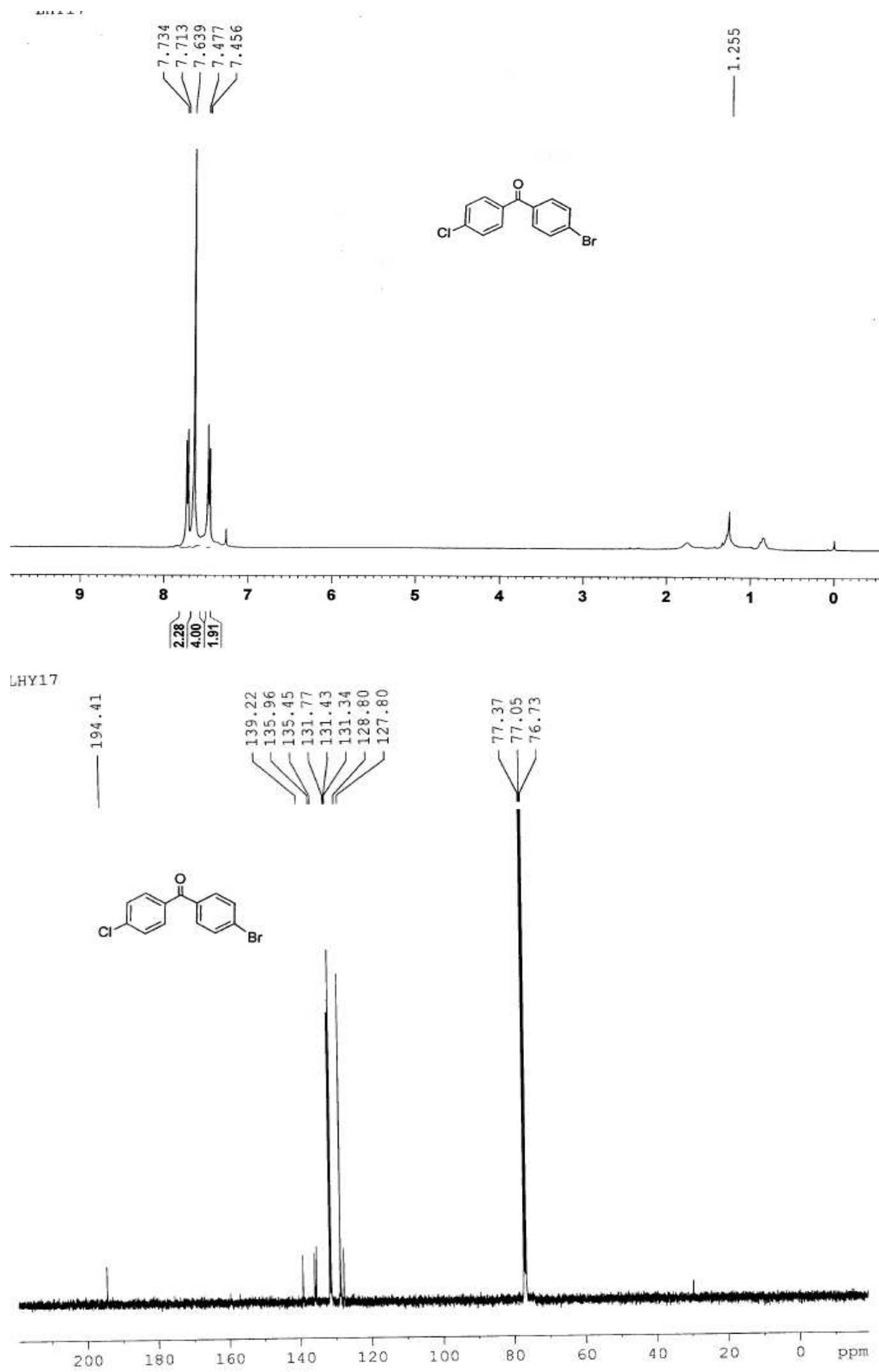

${ }^{1} \mathrm{H}$ NMR and ${ }^{13} \mathrm{C}$ NMR spectra of compound $\mathbf{3 u}$ 

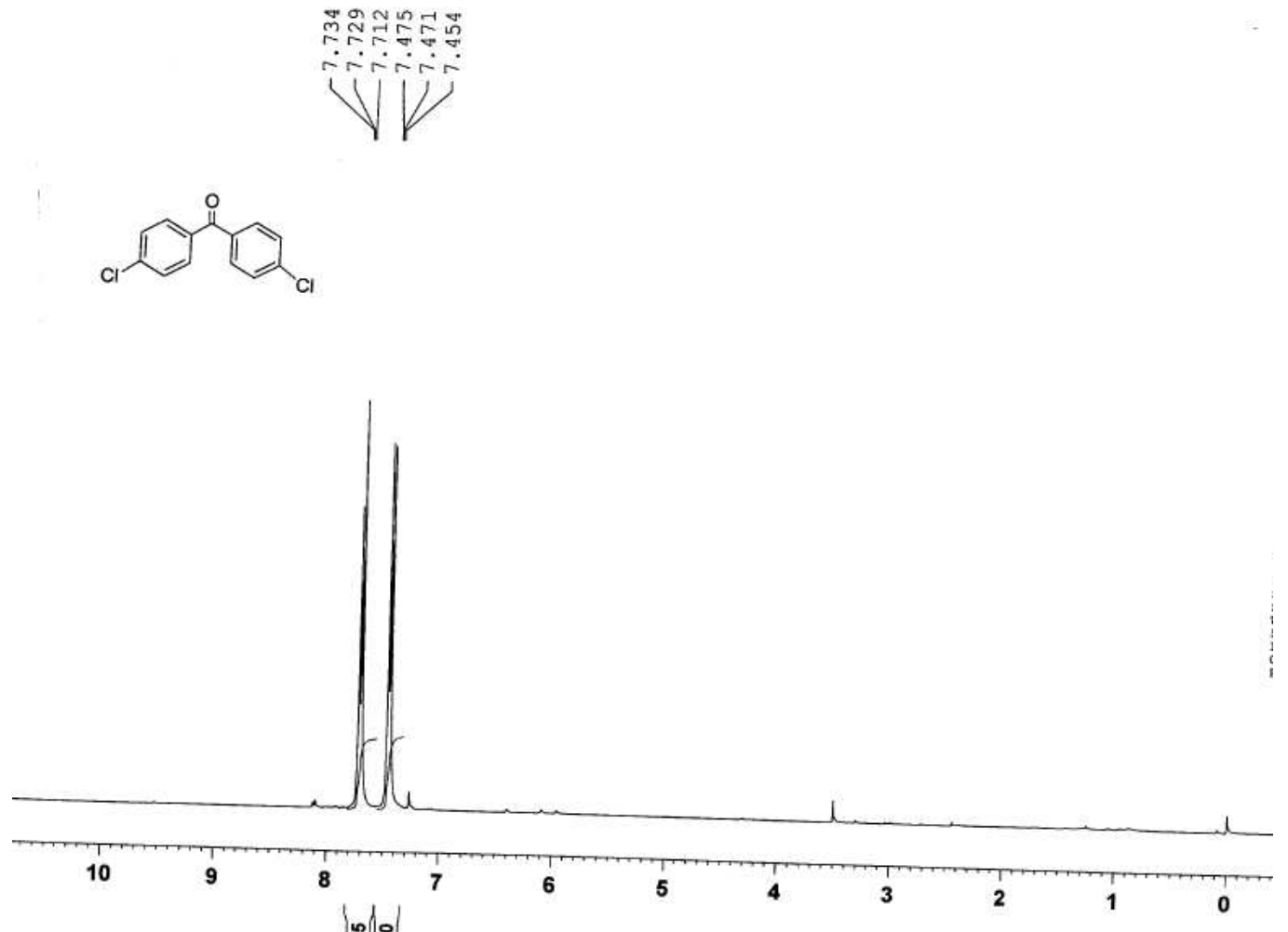

承这

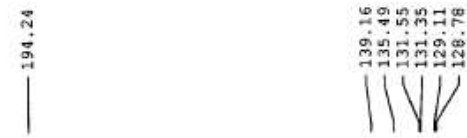

tog

FF⿱

V
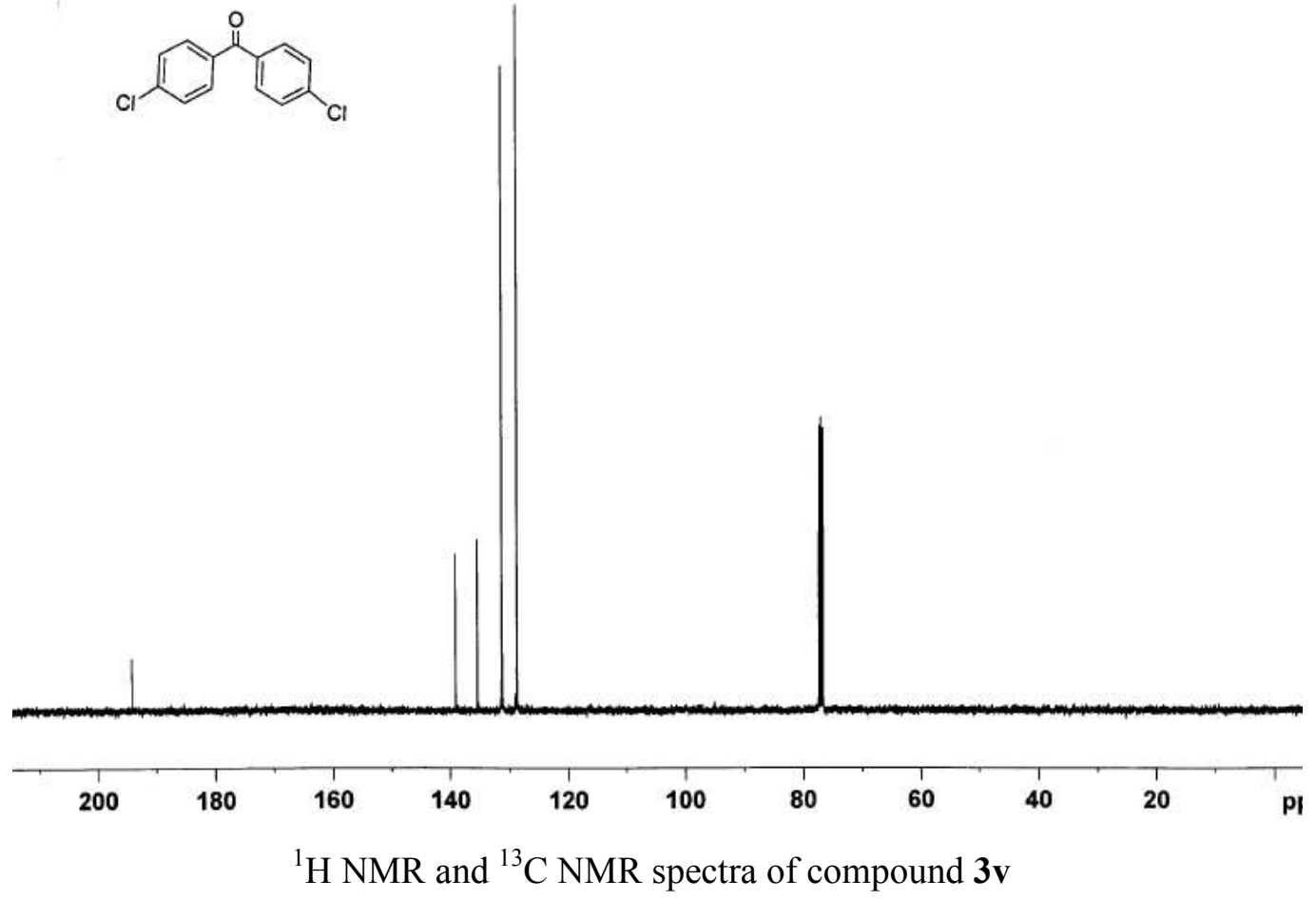


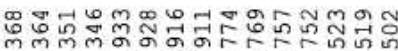

क

WUV
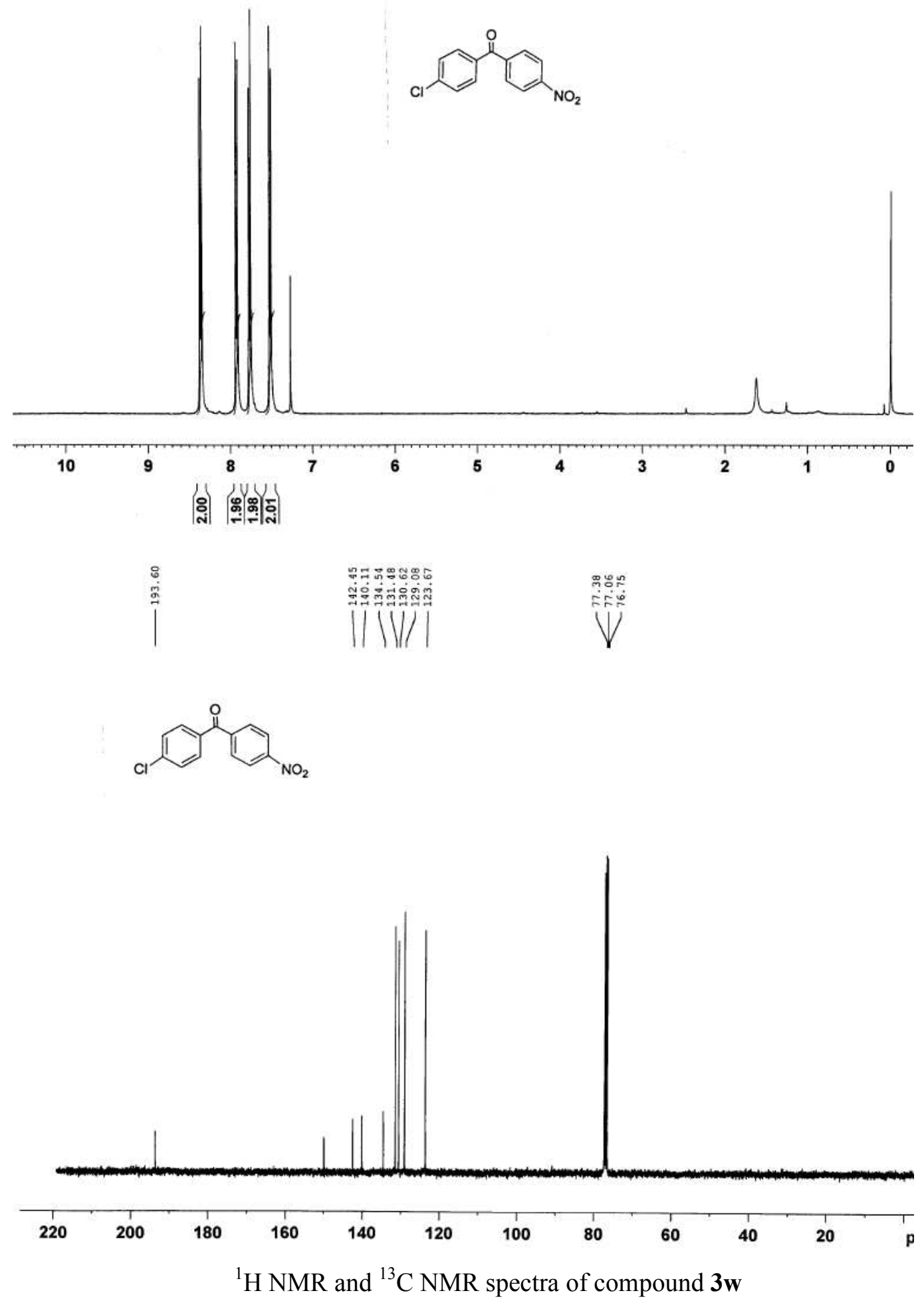

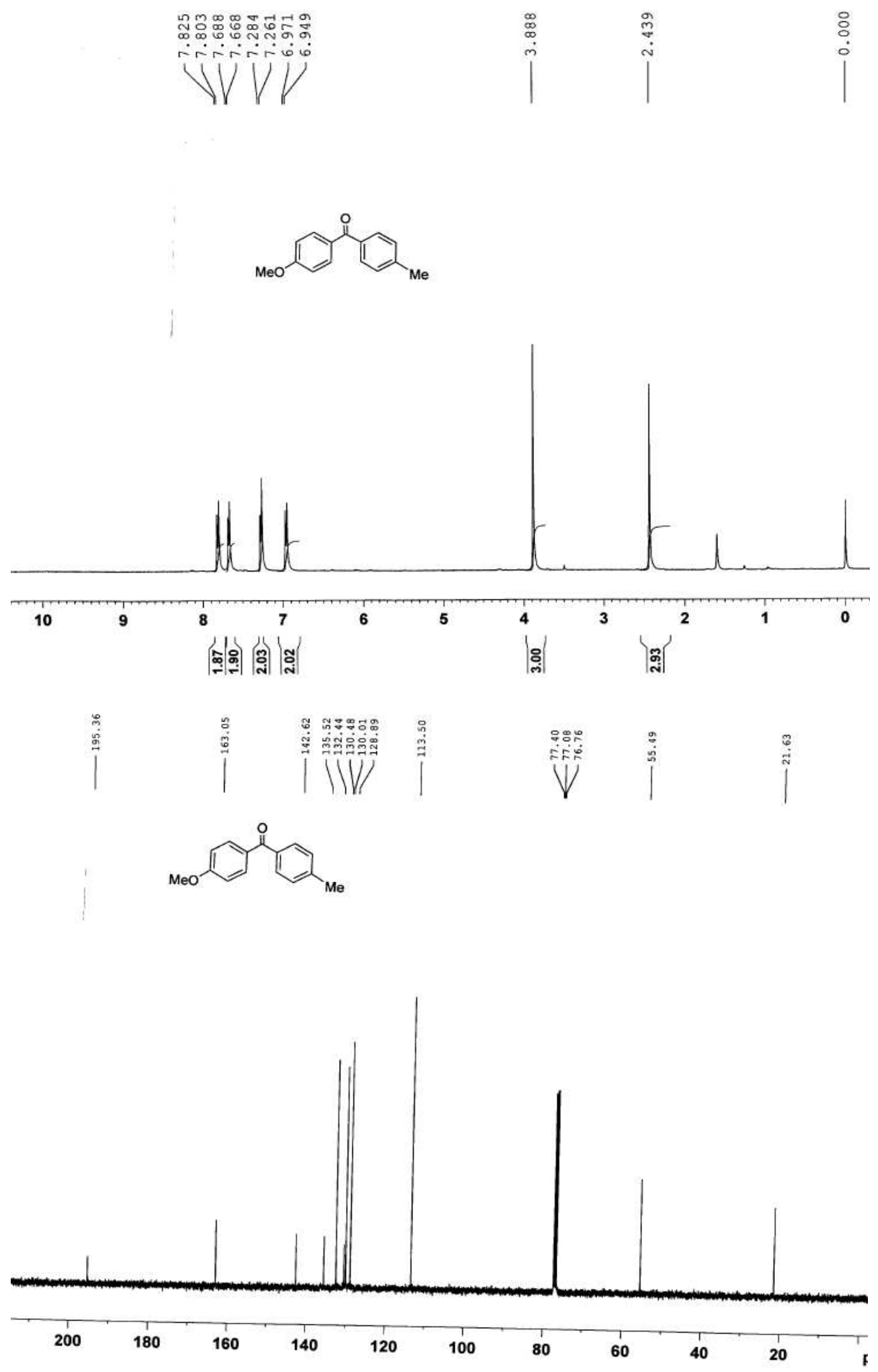

${ }^{1} \mathrm{H}$ NMR and ${ }^{13} \mathrm{C}$ NMR spectra of compound $\mathbf{3 x}$ 


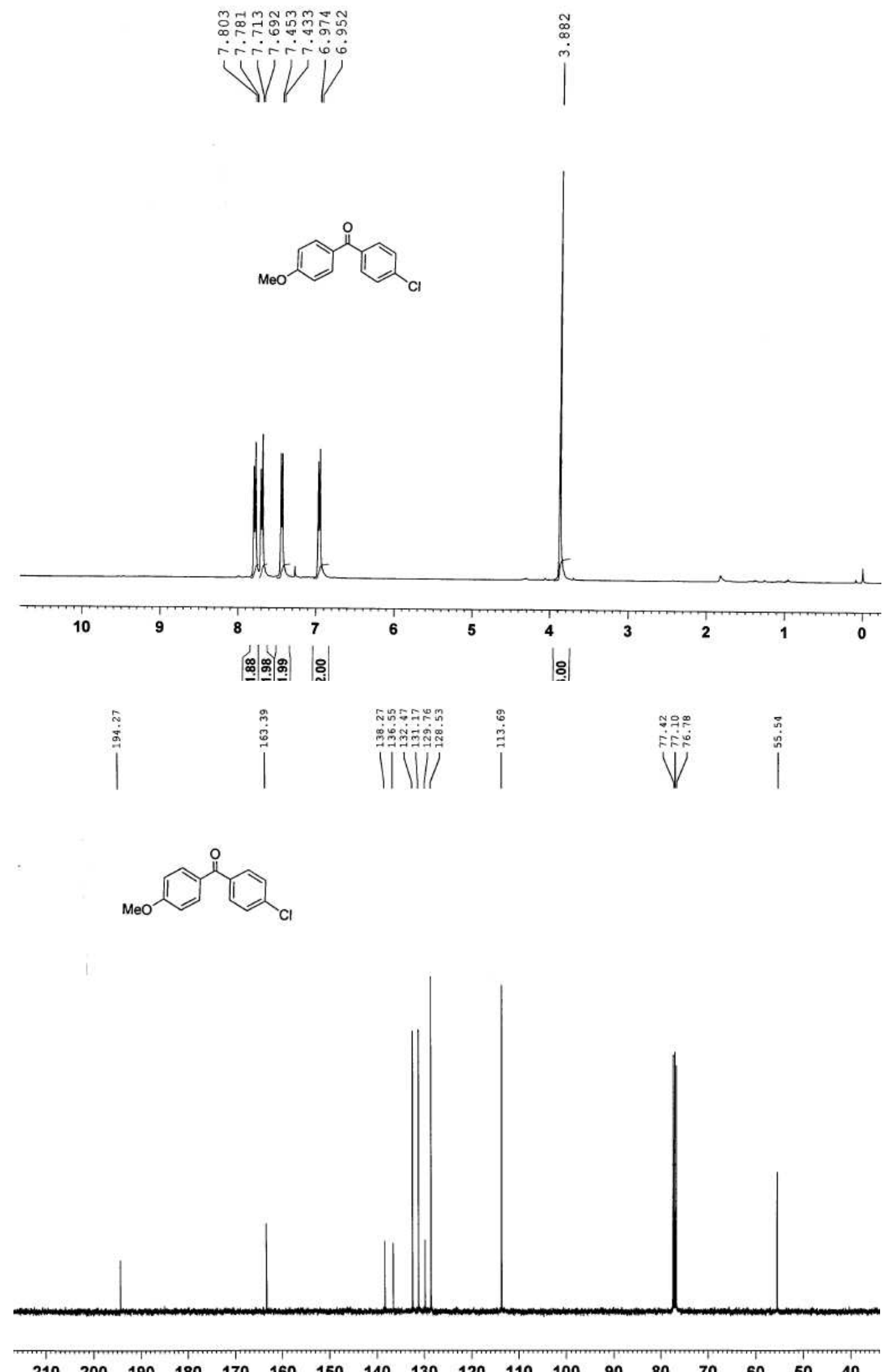

$\begin{array}{llllllllllllllllll}210 & 200 & 190 & 180 & 170 & 160 & 150 & 140 & 130 & 120 & 110 & 100 & 90 & 80 & 70 & 60 & 50 & 40\end{array}$

${ }^{1} \mathrm{H}$ NMR and ${ }^{13} \mathrm{C}$ NMR spectra of compound $\mathbf{3 y}$ 


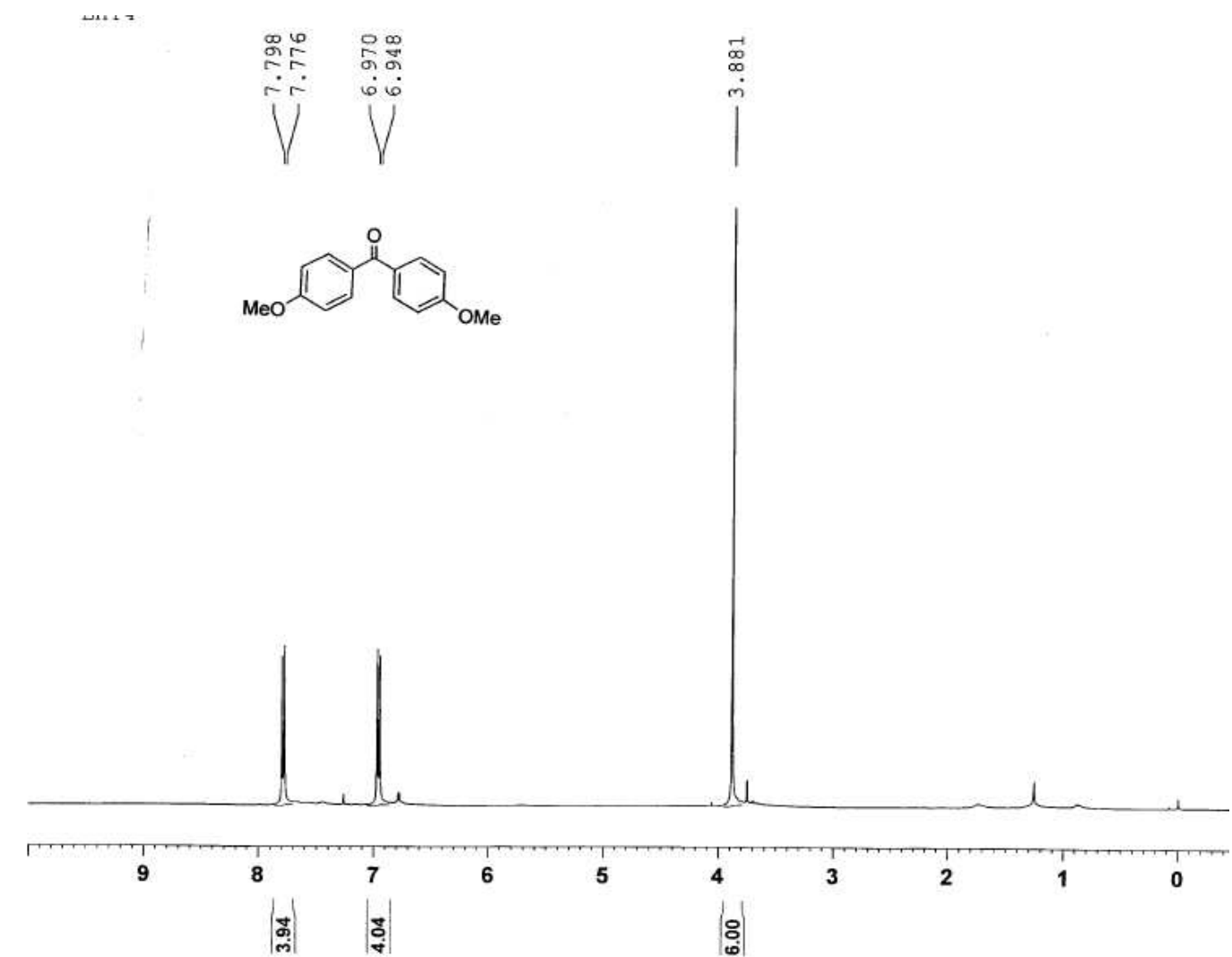

LHY 4
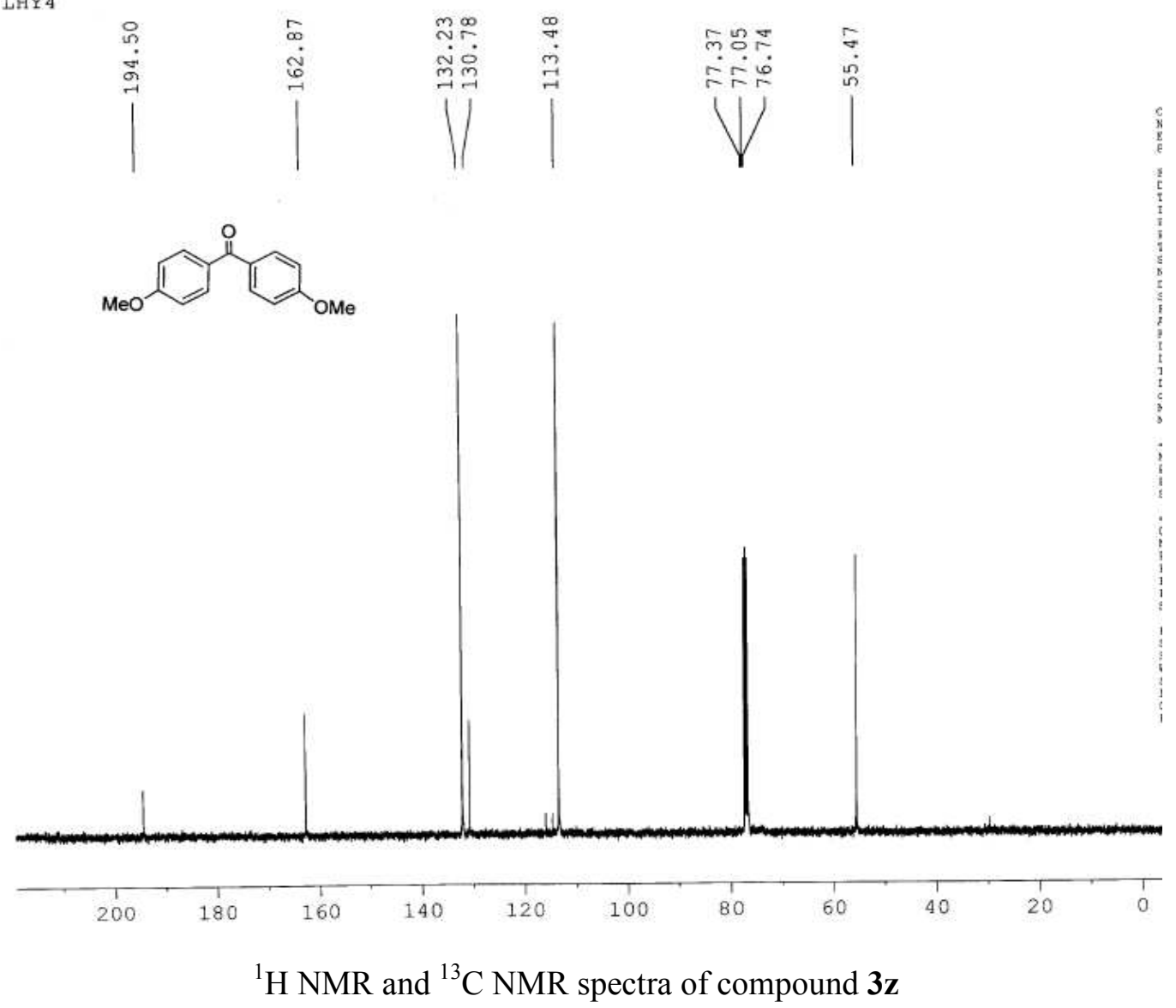


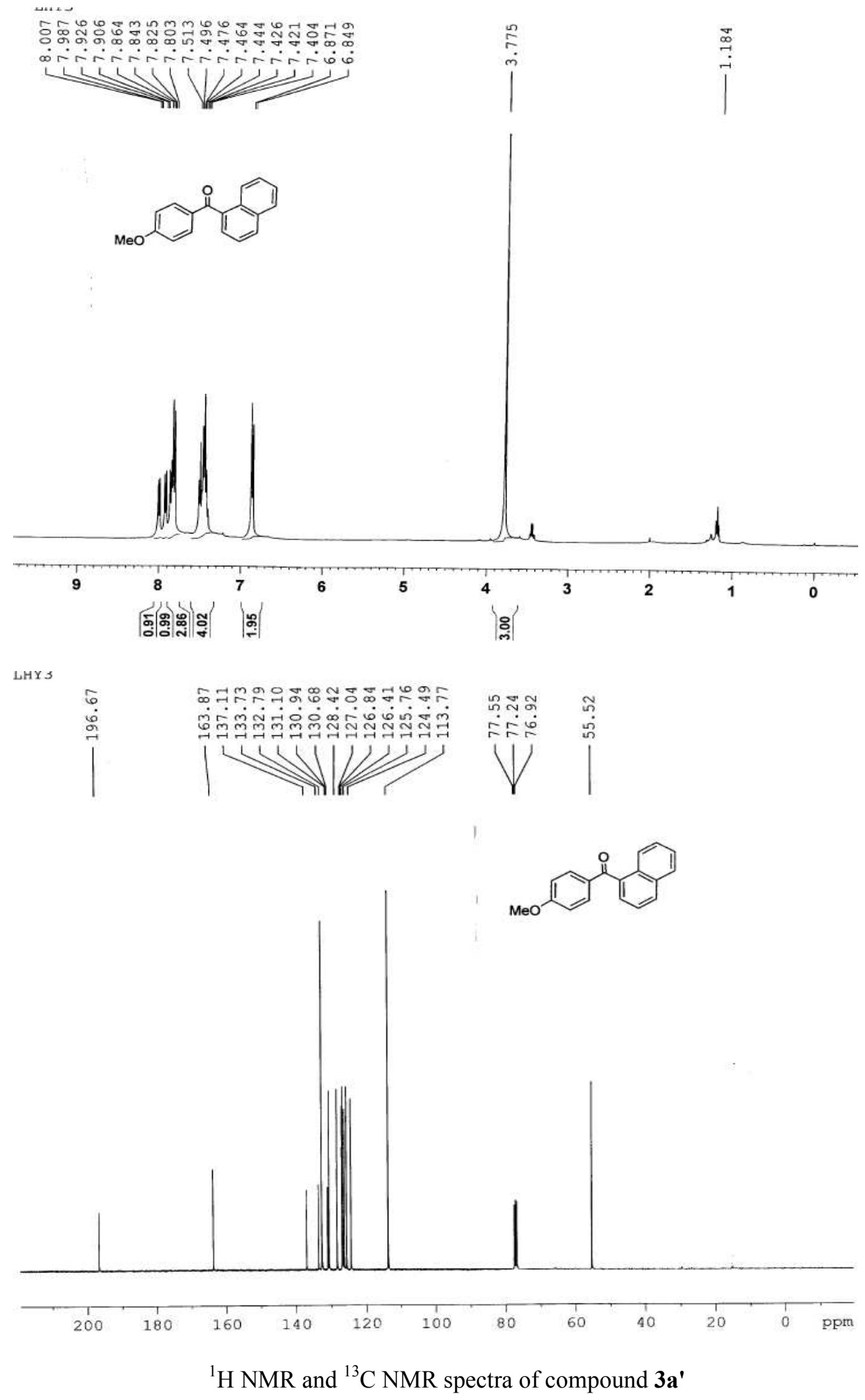



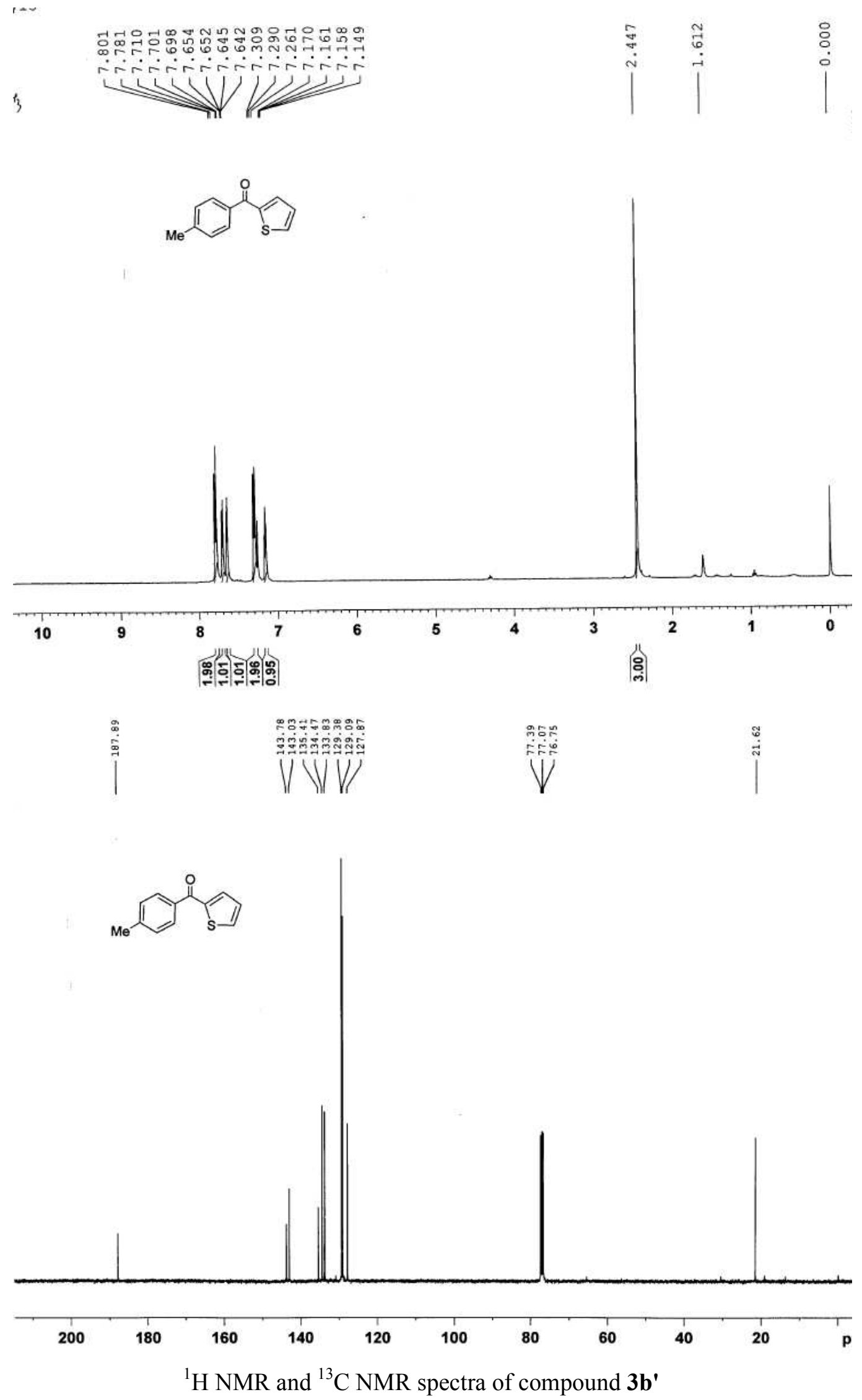

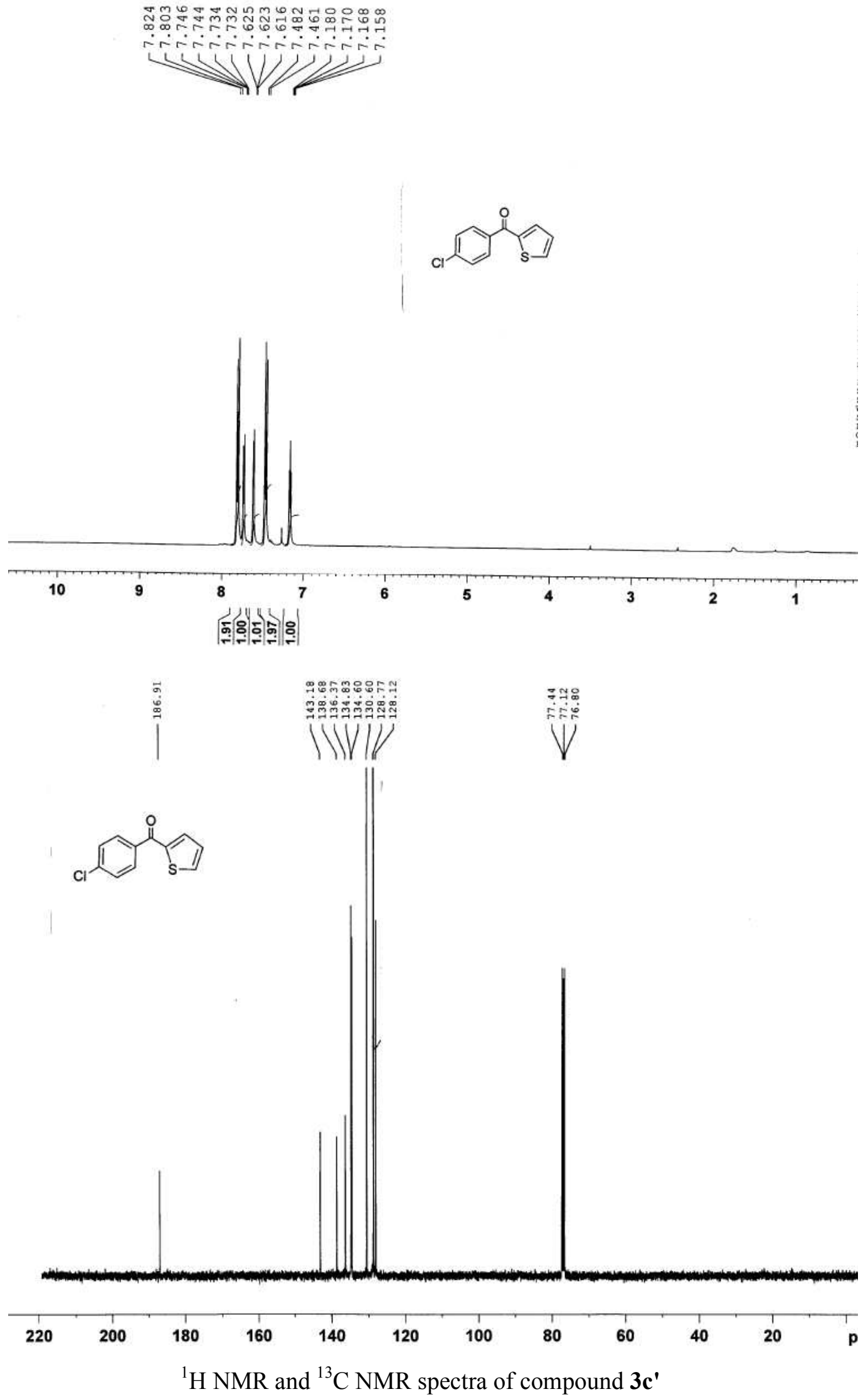


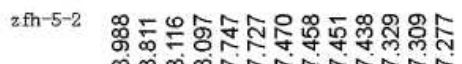

i,

$\int 1 \mid 1$
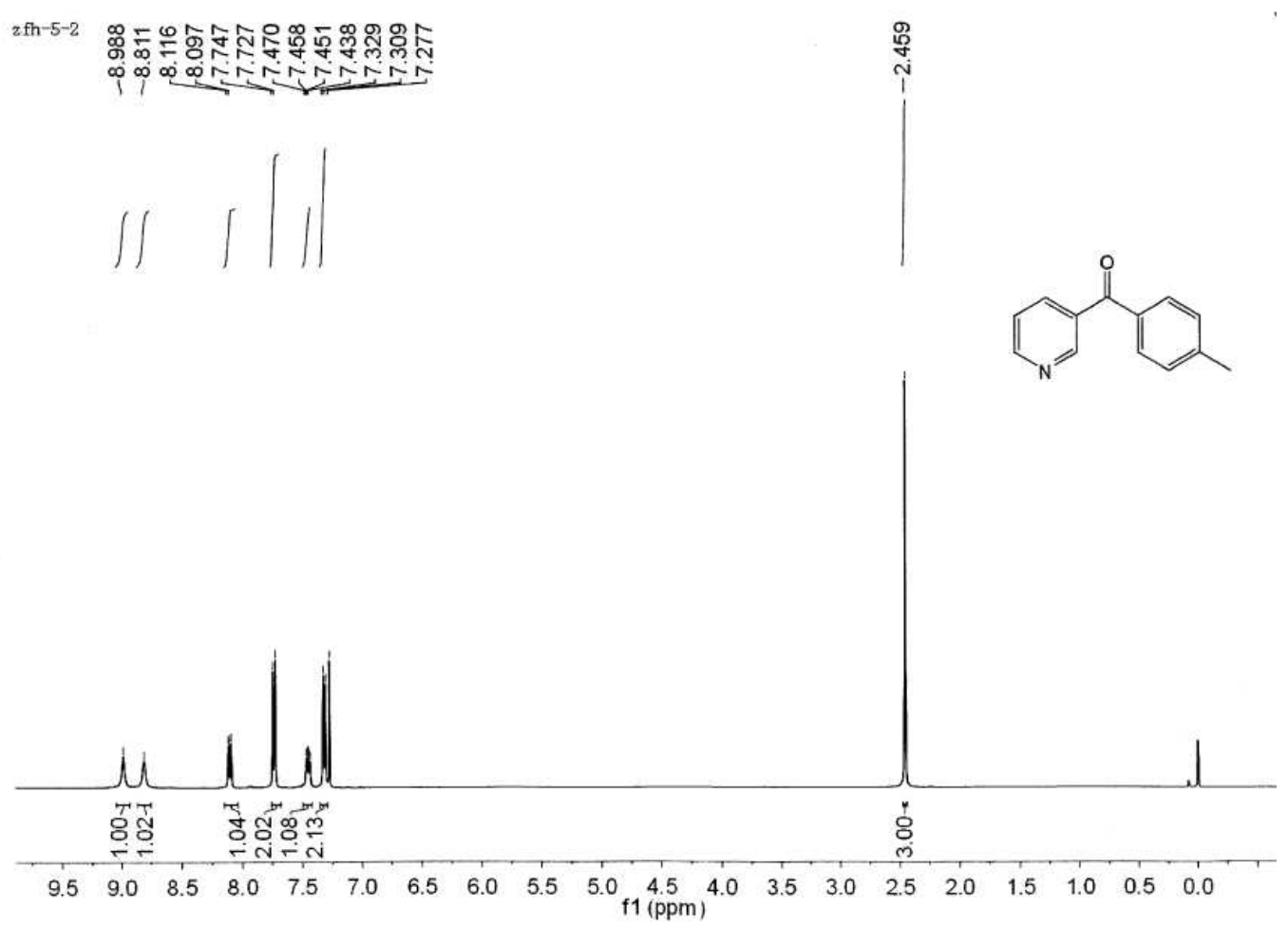

zfh-5-2

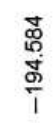

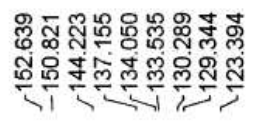

ํํำ

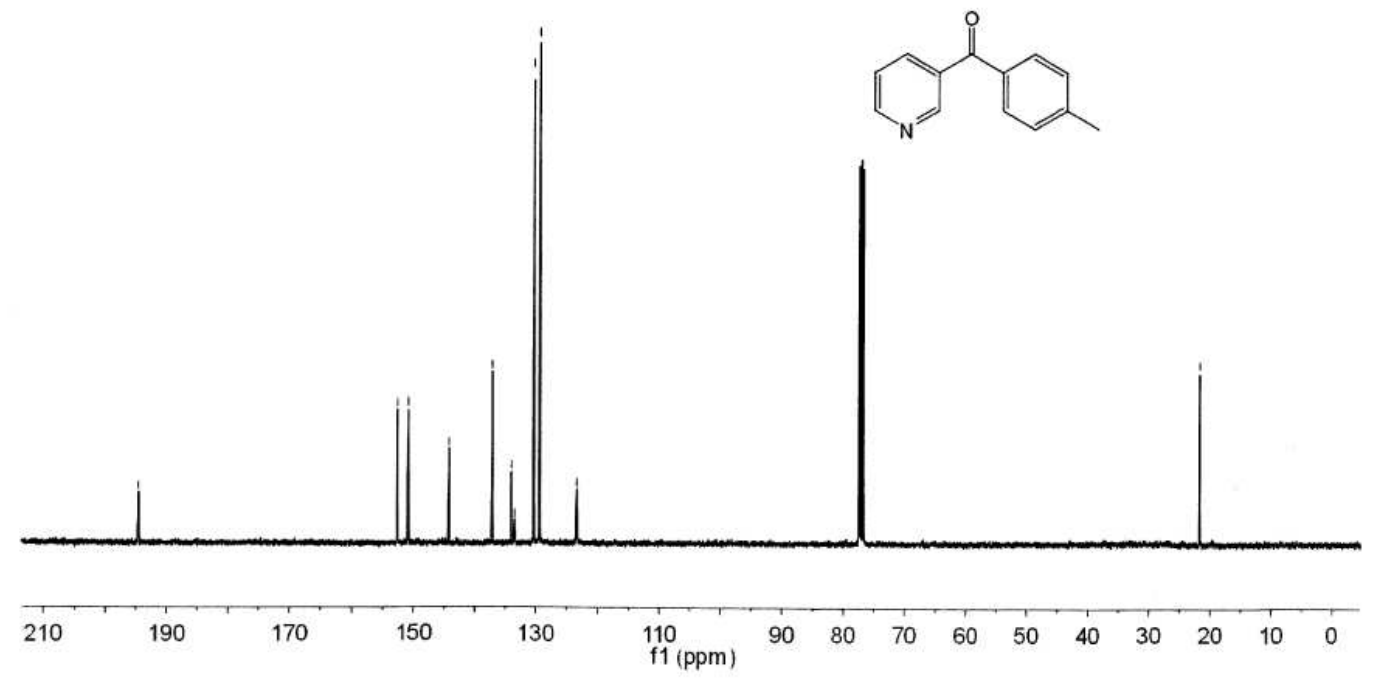

${ }^{1} \mathrm{H}$ NMR and ${ }^{13} \mathrm{C}$ NMR spectra of compound $\mathbf{3 d}$

31 

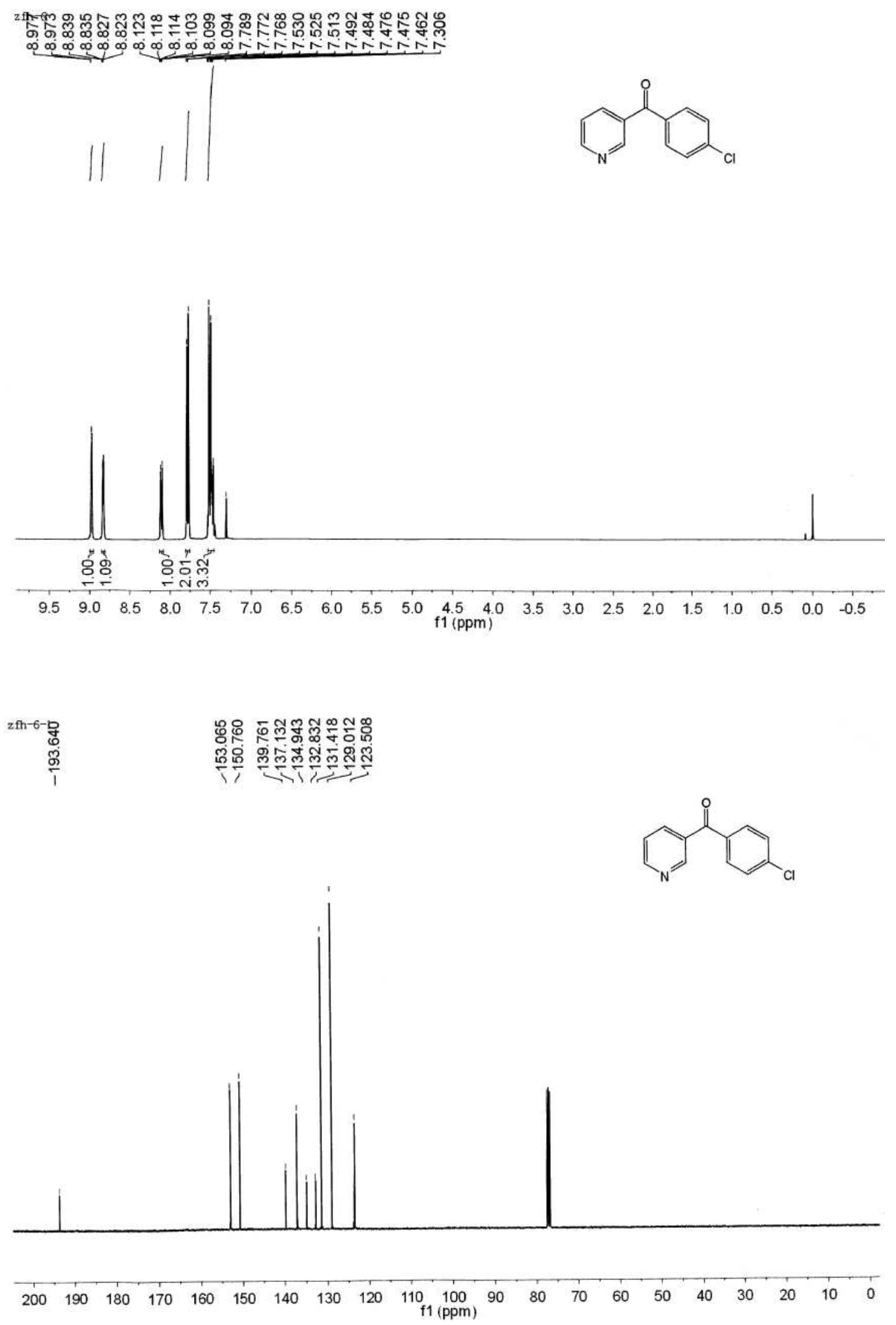

${ }^{1} \mathrm{H}$ NMR and ${ }^{13} \mathrm{C}$ NMR spectra of compound $3 \mathbf{e}^{\prime}$ 

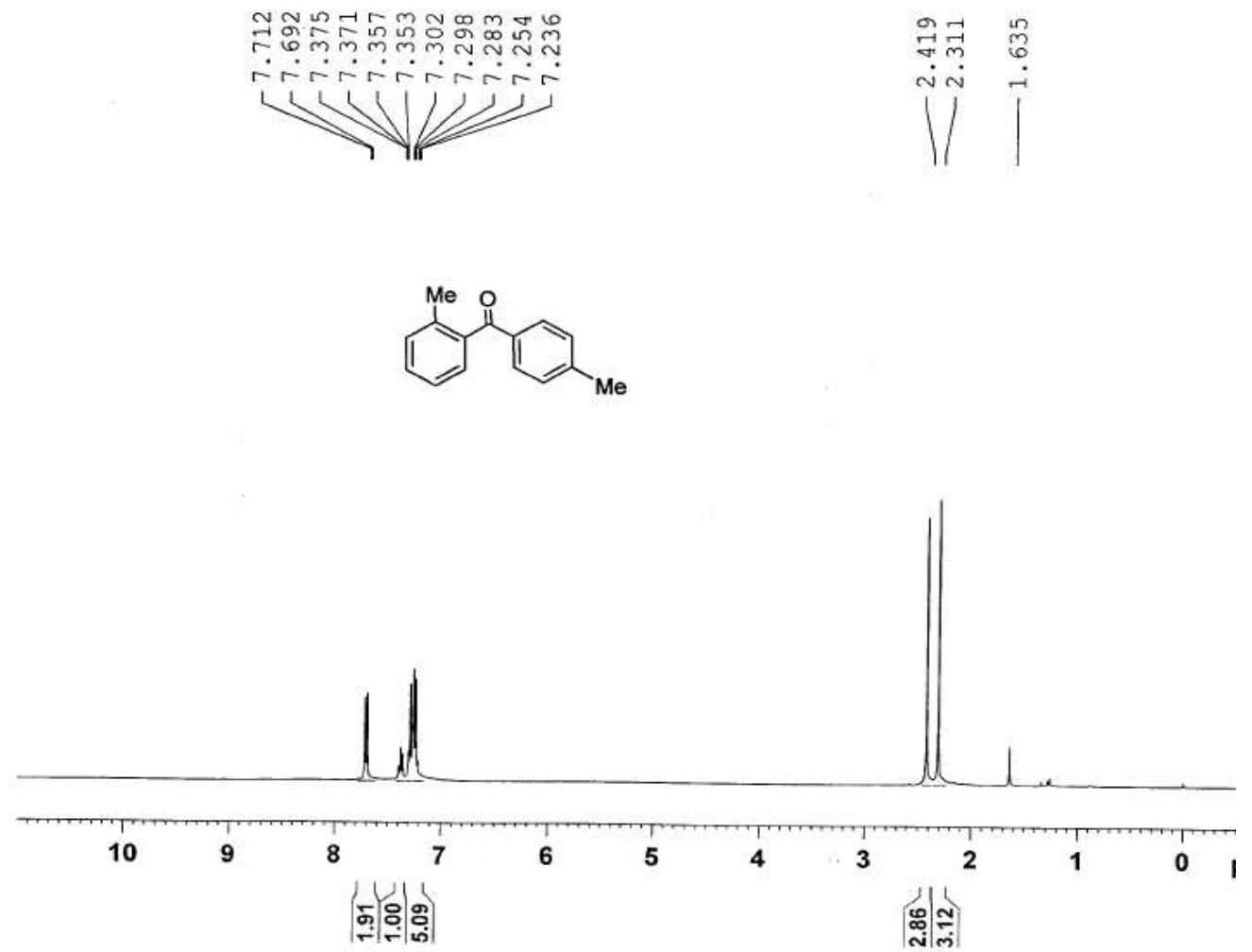

LHY12

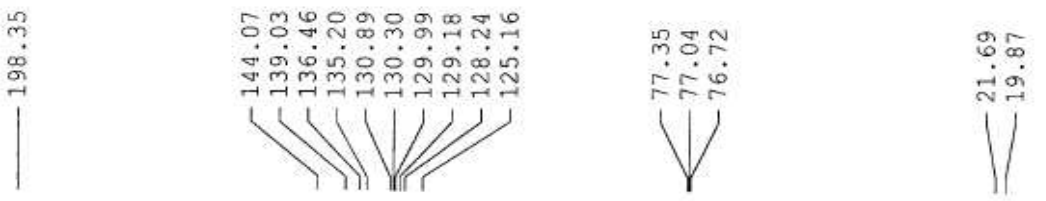

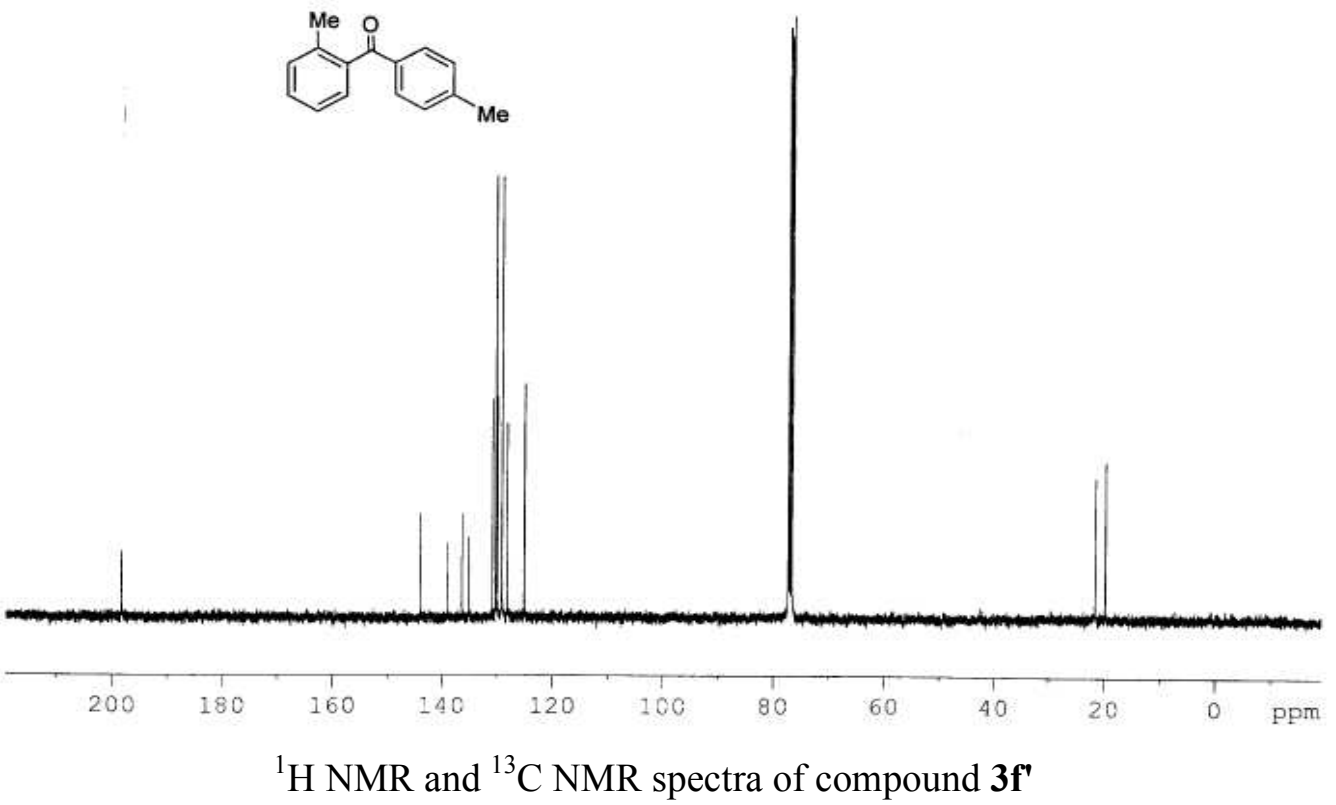




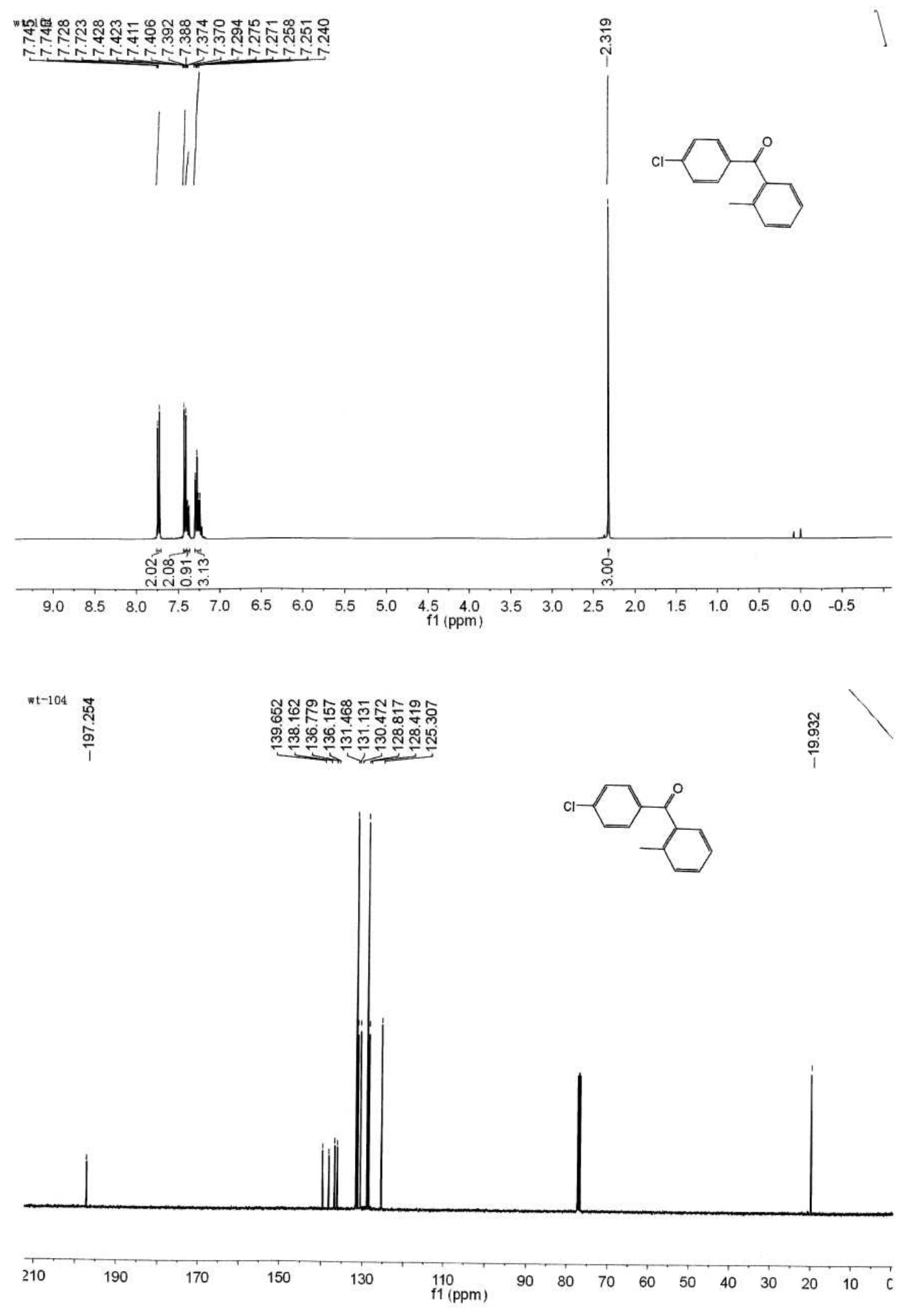

${ }^{1} \mathrm{H}$ NMR and ${ }^{13} \mathrm{C}$ NMR spectra of compound $\mathbf{3 g} \mathbf{g}^{\prime}$ 


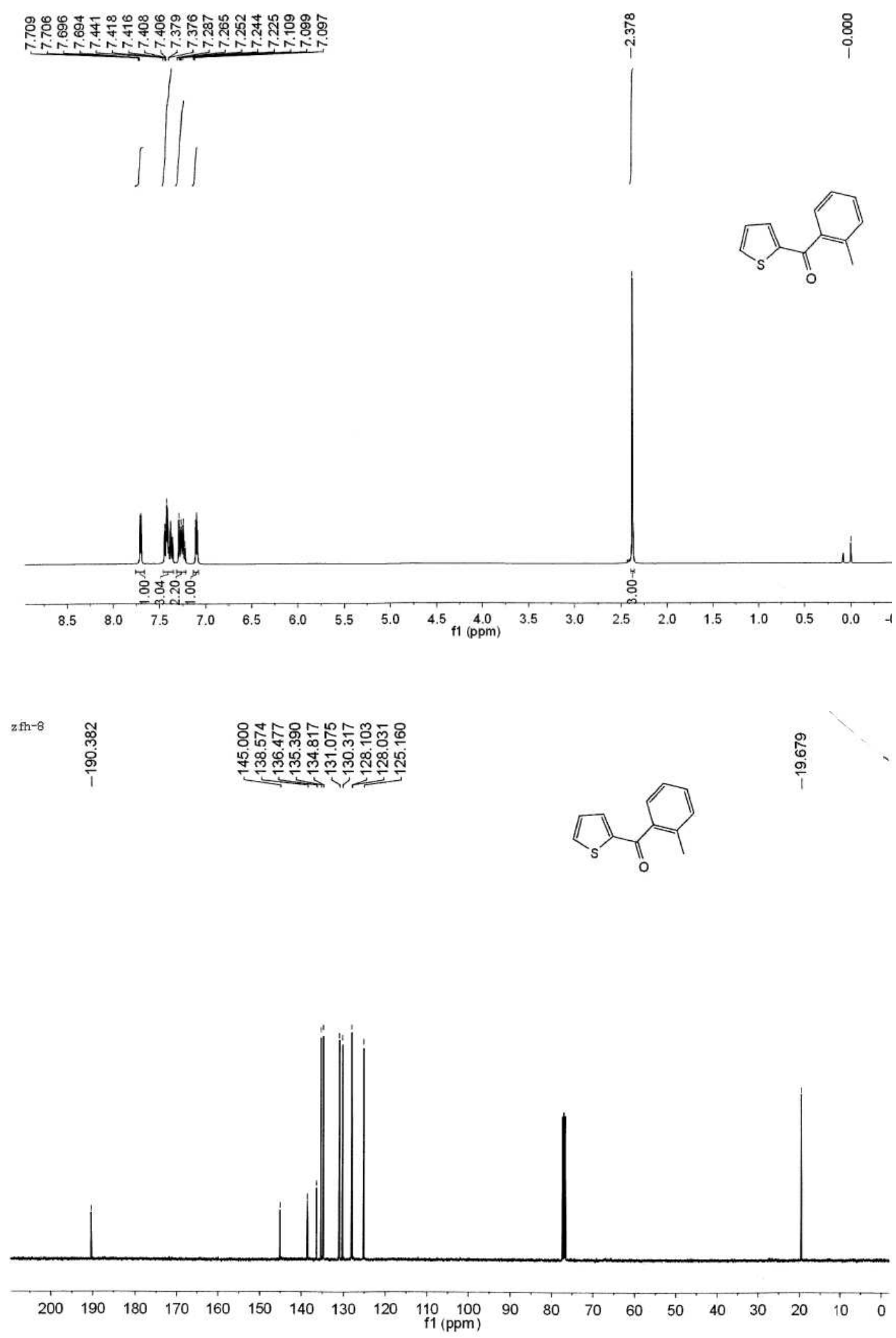

${ }^{1} \mathrm{H}$ NMR and ${ }^{13} \mathrm{C}$ NMR spectra of compound $\mathbf{3 h}{ }^{\prime}$ 


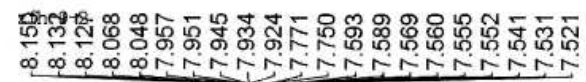
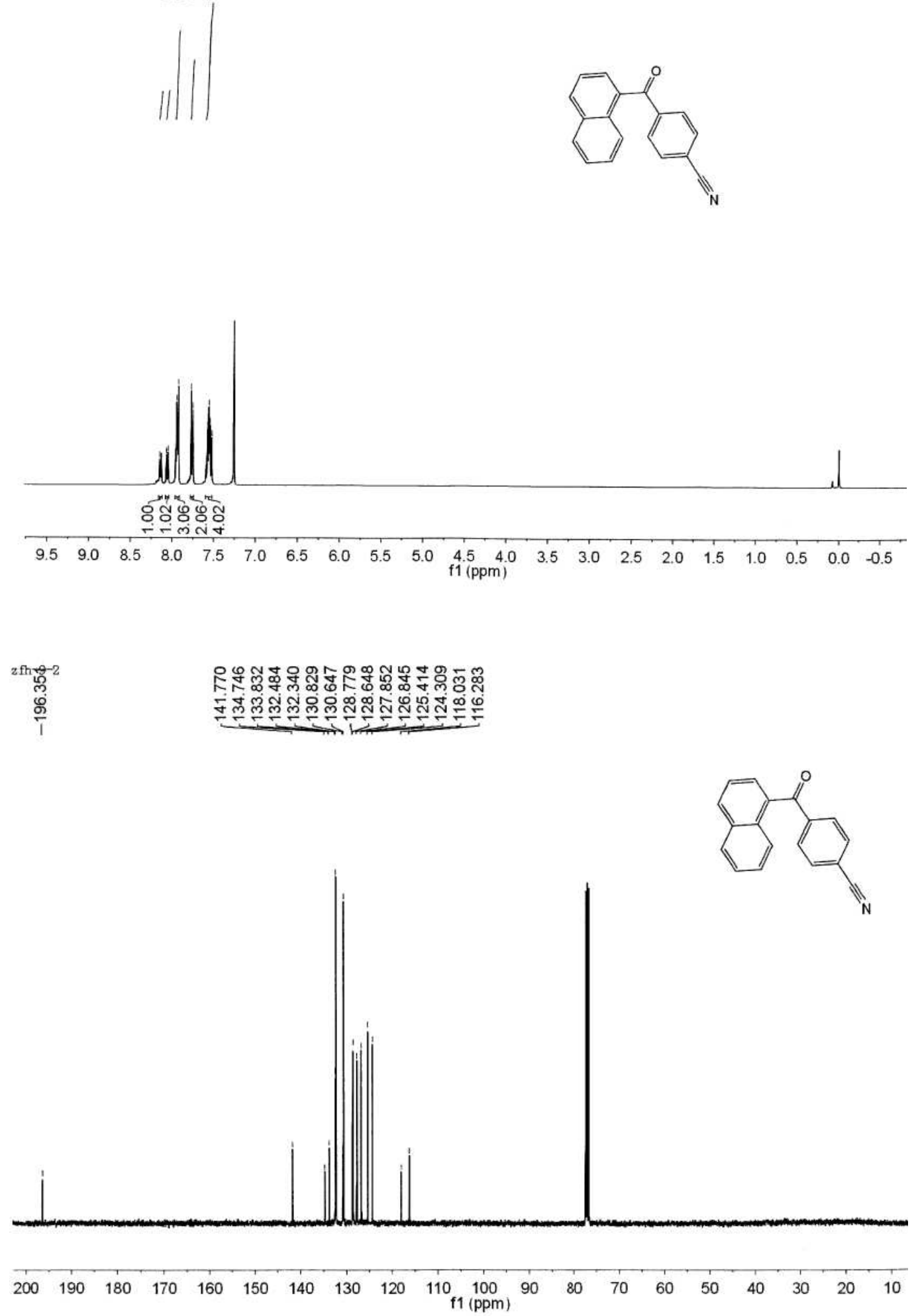

${ }^{1} \mathrm{H}$ NMR and ${ }^{13} \mathrm{C}$ NMR spectra of compound $3 \mathbf{i}^{\prime}$ 

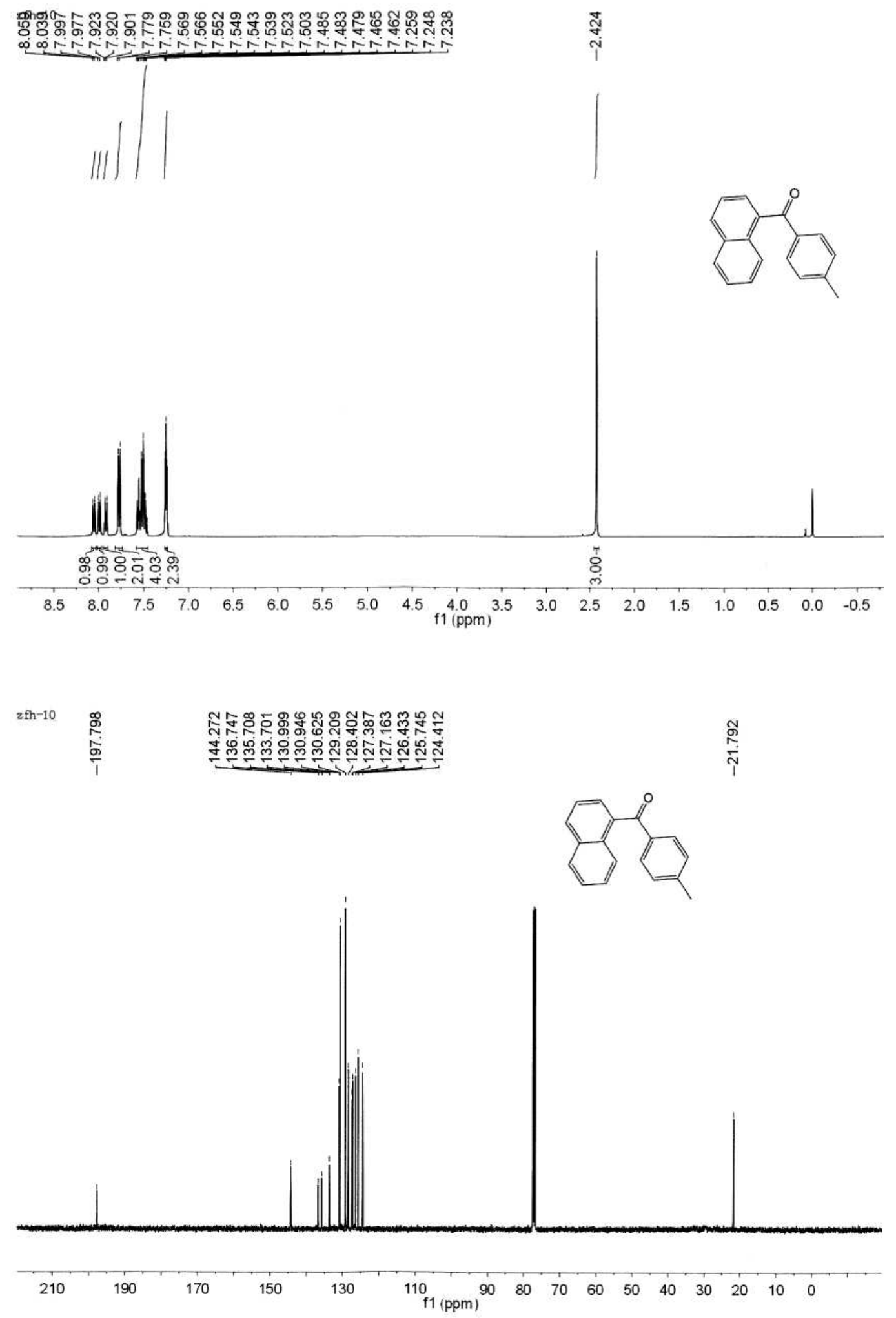

${ }^{1} \mathrm{H}$ NMR and ${ }^{13} \mathrm{C}$ NMR spectra of compound $\mathbf{3 j}$ ' 

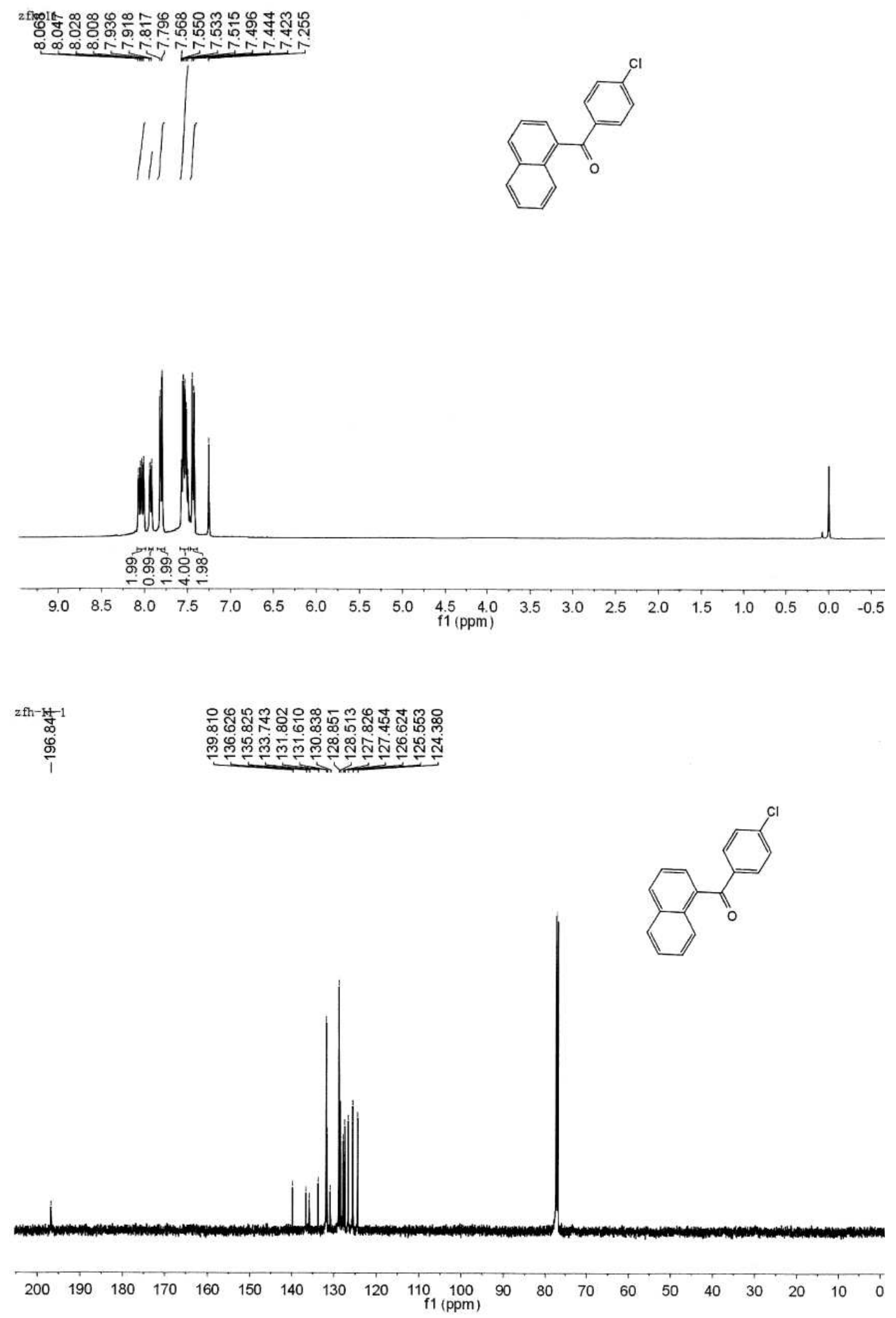

${ }^{1} \mathrm{H}$ NMR and ${ }^{13} \mathrm{C}$ NMR spectra of compound $\mathbf{3} \mathbf{k}^{\prime}$ 